\title{
Limits on the contribution of early endogenous radiolysis to oxidation in carbonaceous chondrites' parent bodies
}

\author{
Alexis Bouquet ${ }^{1,2}$, Kelly E. Miller ${ }^{3}$, Christopher R. Glein $^{3}$, and Olivier Mousis ${ }^{2}$ \\ 1 Aix Marseille Univ, CNRS, PIIM, Marseille, France \\ e-mail: alexis. bouquet@univ-amu.fr \\ 2 Aix Marseille Univ, CNRS, CNES, LAM, Marseille, France \\ ${ }^{3}$ Space Science \& Engineering Division, Southwest Research Institute, San Antonio, TX, USA
}

Received 12 March 2021 / Accepted 26 May 2021

\begin{abstract}
Context. Carbonaceous chondrites have undergone alteration in their parent bodies and display oxidized secondary phases, including sulfates in CI and CM chondrites. The cause of the formation of these sulfates is yet to be determined.

Aims. This study investigates the potential of endogenous radiolysis of water (i.e., radiolysis caused by radionuclides present in the rock) on the parent bodies of carbonaceous chondrites. Radiolysis may have contributed to the enhanced degree of oxidation of CI and $\mathrm{CM}$ chondrites, and we also examined $\mathrm{CV}$ chondrites as a case with no measured sulfates.

Methods. We quantified the oxidants produced by radiolysis and how much of the sulfur content could be oxidized to form sulfates by this method. The amount of oxidants was calculated using a radiolytic production model developed and used for Earth and planetary applications that takes into account relevant physical parameters (water-to-rock ratio, grain density) and composition (amount of radionuclides, sulfur content).

Results. For CM and CI parent bodies, even using a very favorable set of assumptions, only slightly more than $1 \%$ of the available sulfur can be oxidized into sulfates by this process, significantly below the amount of sulfates observed in these chondrites.

Conclusions. Endogenous radiolysis is unlikely to have significantly contributed to the abundance of sulfate in CI and CM meteorites. The hypothesis of oxidation of sulfur by large quantities of $\mathrm{O}_{2}$ accreted with primitive ice, on the other hand, is quantitatively supported by measurements of $\mathrm{O}_{2}$ in comet $67 \mathrm{P} /$ Churyumov-Gerasimenko.
\end{abstract}

Key words. astrochemistry - meteorites, meteors, meteoroids - minor planets, asteroids: general

\section{Introduction}

While carbonaceous chondrites (CC) are some of the most pristine materials available for studying of the origin of our solar system, they have still undergone alteration in their parent bodies as a result of exposure to fluids (Brearley 2006; Krot et al. 2015) or elevated temperatures (Huss et al. 2006). An important feature of $\mathrm{CI}, \mathrm{CM}$, and most $\mathrm{CV}$ chondrites is their relatively oxidized state (Brearley \& Jones 1998); another feature is the presence of oxidized secondary phases in the CM and CI chondrites, attained despite the overall reducing conditions inferred from models of their geochemical evolution during aqueous alteration (Zolensky et al. 1989; Rosenberg et al. 2001). A notable example of this oxidized state in CI and CM chondrites is the presence of sulfates, in which sulfur is in the fully oxidized (+VI) form. The exact cause of the formation of these sulfates has not yet been determined. CV chondrites, on the other hand, do not feature any noticeable amount of sulfates (Gao \& Thiemens 1993; Brearley 2006; Bose et al. 2017). Oxygen isotopic ratios in CM sulfates point to a pre-terrestrial origin via aqueous processes (Airieau et al. 2005). Reports in the literature change through time with regard to the presence of sulfate veins in the CI chondrite falls, suggesting that hypothetical pre-terrestrial sulfates present on the parent body were mobilized and altered once in terrestrial environments (Gounelle \& Zolensky 2001). This interpretation is consistent with their oxygen isotopic composition, with a $\Delta{ }^{17} \mathrm{O}$ that matches terrestrial values (Airieau et al. 2005). Formation of sulfates by disproportionation of elemental sulfur with water is unlikely; experiments indicate it would increase the $\delta^{34} \mathrm{~S}$ (Oana \& Ishikawa 1966), whereas meteoritic sulfates are depleted in ${ }^{34} \mathrm{~S}$ (Monster et al. 1965; Gao \& Thiemens 1993; Labidi et al. 2017), supporting formation via oxidation of sulfides rather than $\mathrm{S}^{0}$. Pre-accretionary formation of sulfates has been suggested in Murchison (Bose et al. 2017) via irradiation of $\mathrm{H}_{2} \mathrm{~S}$ and $\mathrm{SO}_{2}$ ices (Moore et al. 2007), based on slow kinetics for formation of sulfate from oxidation of $\mathrm{HS}^{-}$by water (Ohmoto \& Lasaga 1982) in low-temperature environments consistent with parent body conditions.

In this study, we investigate endogenous radiolysis as a source of reactive oxidants in CC parent bodies (Cody \& Alexander 2005), offering an alternate pathway to aqueous oxidation of sulfides. The source of endogenous radiolysis is the presence of radionuclides such as ${ }^{26} \mathrm{Al}$ in the rock; the decay of these radionuclides irradiates the surrounding water and induces radiation chemistry with the potential to form products such as $\mathrm{H}_{2}, \mathrm{OH}, \mathrm{H}_{2} \mathrm{O}_{2}$, and $\mathrm{HO}_{2}$ (Spinks \& Woods 1990). The effect of this process as a source of $\mathrm{H}_{2}$ has been studied on Earth (Lin et al. 2005a,b; Blair et al. 2007; Sherwood Lollar et al. 2014) and for various planetary environments (Bouquet et al. 2017; Dzaugis et al. 2018; Ray et al. 2021). The irradiation of liquid water offers higher yields of $\mathrm{HO}_{x}$ products than the irradiation of water ice (Spinks \& Woods 1990), as illustrated by the modest potential for chemical modification of cometary ices by this process (Bouquet et al. 2018). The period of early aqueous alteration 
in $\mathrm{CC}$ parent bodies is correlated with intense radiation output by short-lived radionuclides ${ }^{26} \mathrm{Al}$ and ${ }^{60} \mathrm{Fe}$, whose energy caused the melting of the ice in the first place. This period of aqueous alteration is thought to have begun shortly after the accretion of the parent bodies, a few million years after the formation of calcium-aluminum inclusions (CAI) (Jilly et al. 2014).

As a proxy for the oxidizing potential of endogenous radiolysis in this context, we focus on the possibility of oxidizing the CC sulfides to form sulfates. This process is known to happen in terrestrial environments ( $\mathrm{Li}$ et al. 2016). Oxidation of pyrite into sulfates in the context of acid mine drainage is a common phenomenon and an environmental problem here on Earth (Belzile et al. 1997). The $\mathrm{H}_{2} \mathrm{O}_{2}$ produced by radiolysis of water has been observed to efficiently oxidize sulfur in the form of troilite (Lewis 1967), and production of sulfates from $\gamma$ irradiation of pyrite-water has been experimentally demonstrated (Lefticariu et al. 2010). Oxidation of pyrrhotite in aqueous solution has also been shown to produce sulfates (Belzile et al. 2004). To our knowledge the isotopic effect of sulfide oxidation through radiolysis has only been investigated for pyrite oxidation (Lefticariu et al. 2010; Li et al. 2016), while pyrrhotite is the most common sulfide in chondrites; this means that the isotopic composition of chondritic sulfates (with results differing between studies; see Monster et al. 1965; Gao \& Thiemens 1993; Bullock et al. 2010) neither supports nor excludes a radiolytic origin. We constrain the amount of sulfates that can be formed with the calculated production of oxidants in conditions relevant to CI, CM, and $\mathrm{CV}$ parent bodies and compare it to the total amount of sulfur present (measured in pulverized samples, and therefore including all forms of sulfur; see Dreibus et al. 1995 for an example of the measurement methods).

In Sect. 2, we present the model of radiolytic production and the set of assumptions adopted for conditions in the CI, CM, and CV parent bodies. Section 3 is dedicated to the calculation results, and Sect. 4 discusses the implications of our findings, and examines the possibility of accreted $\mathrm{O}_{2}$ as an alternative means of production for sulfate.

\section{Model and assumptions}

\subsection{Model of radiolytic production}

To assess the potential production of oxidants and subsequently sulfates in the CC parent bodies, we use a model of radiolytic production developed for Earth and planetary applications (Hoffman 1992; Lin et al. 2005a; Blair et al. 2007; Bouquet et al. 2017, 2018). We refer the reader to these works for a more detailed explanation of the model, and we reproduce here only the main equations resulting in $Y_{p}$ (in molecules per unit of time per unit of volume of material) of a given product $p$,

$Y_{p}=\sum_{s, i} G_{p, i} D_{s, i}$

where $G_{p, i}$ is the experimental yield of product $p$ due to radiation type $i$ (e.g., $G_{\mathrm{H}_{2} \mathrm{O}_{2}, \gamma}$ is the yield of hydrogen peroxide from the irradiation of water by $\gamma$ rays) in molecules per unit of energy and $D_{s, i}$ is the amount of energy deposited into water by radionuclide type $s$ emitting radiation type $i$, calculated as

$D_{s, i}=\frac{\rho_{r} A_{s}\left(\sum E\right)_{i, s}}{\frac{1}{1-\phi}+\frac{1}{S_{i}^{\prime} \phi}}$,

where $\rho_{r}$ is the grain density, $A_{s}$ is the radiation activity of species $s$ (decays per unit of time per unit of mass of rock; this is a notion separate from the thermodynamic activity), $\left(\sum E\right)_{i, s}$ is the energy emitted by species $s$ as radiation type $i$ over one chain of decay (energy, we use the values tabulated in Bouquet et al. 2018), $\phi$ is the ratio of the volume occupied by water to the total volume (water + rock), and $S_{i}^{\prime}$ is the ratio of stopping powers of radiation $i$ (stopping power in water to stopping power in rock).

We calculate the production of the two most abundant oxidants $\mathrm{OH}$ and $\mathrm{H}_{2} \mathrm{O}_{2}$, with the following yields (all in molecules/100 eV) (Spinks \& Woods 1990): $G_{\mathrm{OH}, \beta}=G_{\mathrm{OH}, \gamma}=2.72, \quad G_{\mathrm{OH}, \alpha}=0.5, \quad G_{\mathrm{H}_{2} \mathrm{O}_{2}, \beta}=G_{\mathrm{H}_{2} \mathrm{O}_{2}, \gamma}=0.68$, $G_{\mathrm{H}_{2} \mathrm{O}_{2}, \alpha}=1.45$. Due to its much lower yields, we neglect the production of $\mathrm{HO}_{2}$. While $\mathrm{O}_{2}$ appears in water radiolysis experiments, it is not a primary product (Spinks \& Woods 1990) and counting its yield would be redundant.

The quantity of sulfates produced is based on the amount of oxygen atoms in the oxidants produced (two $\mathrm{H}_{2} \mathrm{O}_{2}$ or four $\mathrm{OH}$ are required to form one sulfate). Ideally, the quantity of sulfates produced would be determined through a known reaction mechanism. In this section we discuss oxidation of iron monosulfides $\left(\mathrm{Fe}_{(1-x)} \mathrm{S}\right.$, for $x=0$ to 0.125$)$, since pyrrhotite is the most common sulfide in CC chondrites as indicated by recent Position Sensitive Detector-X-Ray Diffraction (PSD-XRD) studies (Bland et al. 2004; King et al. 2015; Donaldson Hanna et al. 2019). We include the discussion of oxidation involving $\mathrm{O}_{2}$. While not directly applicable to the context of endogenous radiolysis, it should be considered when assuming that significant amounts of $\mathrm{O}_{2}$ were initially present, which is the hypothesis we present in Sect. 4.2. Moreover, this is the most widely studied sulfide oxidation process (Belzile et al. 2004), and the literature is much sparser when it comes to anoxic conditions. Significant sulfate production was observed when immersing pyrrhotite $(x=0.11)$ into a hydrogen peroxide solution for as little as 5 min (Buckley et al. 1985). The same study also determined that sulfates were the main product of oxidation of pyrrhotite by $\mathrm{O}_{2}$ in an ammonia solution. In the case of aqueous solutions rich in $\mathrm{O}_{2}$ (see Belzile et al. 2004 and references therein), oxidative dissolution of pyrrhotite occurs and produces sulfates, but at low $\mathrm{pH}$ acidic dissolution becomes important. Experiments at low $\mathrm{pH}$ with $\mathrm{O}_{2}$ show that a large part of the sulfides are oxidized into an elemental sulfur form, a product observed in most experiments of pyrrhotite oxidation. Through mass balance calculation (rather than direct measurement of $S^{0}$ ), Janzen et al. (2000) evaluate that up to $86 \%$ of the oxidized sulfides in their experiments ended up as elemental sulfur. Oxidation of $\mathrm{CV}$ chondrite samples in an $\mathrm{O}_{2}$ rich aqueous solution (Jones \& Brearley 2006) led to the production of sulfates, with the pyrrhotite oxidation net reaction described as

$\mathrm{Fe}_{0.875} \mathrm{~S}+0.125 \mathrm{H}_{2} \mathrm{O}+1.938 \mathrm{O}_{2}=0.25 \mathrm{H}^{+}+0.875 \mathrm{Fe}^{2+}+\mathrm{SO}_{4}^{2-}$,

which is described in more general terms by Janzen et al. (2000) for the low $\mathrm{pH}$ oxidation of pyrrhotite. No elemental sulfur is mentioned in the results of Jones \& Brearley (2006).

While sulfate-producing oxidation of troilite (FeS) by $\mathrm{H}_{2} \mathrm{O}_{2}$ in aqueous, alkaline solutions has been experimentally observed (Lewis 1967), to our knowledge an exact mechanism has not been determined. Baikova et al. (2009), performing $\mathrm{H}_{2} \mathrm{O}_{2}$ oxidation of troilite, observed primarily the formation of elemental sulfur, sulfide ions, and thiosulfate, and hypothesized the production of sulfoxylate ions $\mathrm{HSO}_{2}^{-}$, but did not discuss sulfate formation. Chiriţă \& Descostes (2006) determined a mechanism for troilite oxidation in acidic conditions, where acidic dissolution of troilite is a key first step. The conditions of hydrothermal alteration in 
CC parent bodies are generally thought to be alkaline as a result of the interaction with rocks, but early acidic conditions are possible (Zolotov \& Mironenko 2007). It is possible to obtain an upper bound to the amount of sulfates that can be produced by considering the net reactions to amount to

$\mathrm{S}(-\mathrm{II})+2 \mathrm{H}_{2} \mathrm{O}_{2} \rightleftharpoons \mathrm{SO}_{4}^{2-}+2 \mathrm{H}_{2}$,

$\mathrm{S}(-\mathrm{II})+4 \mathrm{OH} \rightleftharpoons \mathrm{SO}_{4}^{2-}+2 \mathrm{H}_{2}$.

We also do not take into account the likely competition for oxidants from other species (Ray et al. 2021). In the case of pyrrhotite oxidation it seems inevitable that iron would get oxidized as well, and Baikova et al. (2009) observed the formation of ferric hydroxide when large amounts of $\mathrm{H}_{2} \mathrm{O}_{2}$ were added to their solutions. Similarly, Hamilton \& Woods (1981) observed that the oxidation of pyrrhotite in alkaline solutions was strongly inhibited by the precipitation of ferric oxide onto the mineral surface; the experiments of Jones \& Brearley (2006) also produced large quantities of ferric oxides. In the context of the alteration of CC parent bodies, some of the iron may have been incorporated into magnetite, which is found in large quantities in particular in CI chondrites (Hyman \& Rowe 1983; Hua \& Buseck 1998). In acidic conditions, ferric ions stay in solution and oxidize more pyrrhotite (Belzile et al. 2004), and the oxidation of pyrrhotite by $\mathrm{Fe}^{3+}$ at low $\mathrm{pH}$ actually proceeds faster than by $\mathrm{O}_{2}$ (Janzen et al. 2000). The Belzile et al. (2004) review also indicates that in numerous experiments large amounts of elemental sulfur were produced, which is at odds with its relatively low abundance in CI and CM chondrites related to sulfates and sulfides (DuFresne \& Anders 1962; Kaplan \& Hulston 1966; Fredriksson \& Kerridge 1988; Burgess et al. 1991; Labidi et al. 2017). However, the measurements yield a wide range of different results, from $0.1 \mathrm{wt} \%$ (Fredriksson \& Kerridge 1988) to $1.44 \mathrm{wt} \%$ (Kaplan \& Hulston 1966); the highest values may be consistent with sulfate production being accompanied by elemental sulfur production. We therefore note that the values we obtain with our assumptions are upper limits.

\subsection{Assumptions on parent bodies}

The model described in Sect. 2.1 requires several inputs discussed below.

Grain density $\rho_{r}$. We note that the grain density values measured in CM and CI chondrites are representative of the material after alteration; the value of $\rho_{r}$ at the onset of aqueous alteration, which is the time period to be modeled, is likely to be different and generally higher. We consider two bounds for $\rho_{r}$ : the contemporary measured values, and $3.5 \mathrm{~g} \mathrm{~cm}^{-3}$, which corresponds to $\mathrm{CV}$ chondrites (anhydrous and therefore the closest direct indication available of the density of the original material).

Activity $A_{s}$ of each species $s$ (decays $s^{-1} g^{-1}$ ). The main input to determine is the initial amount of radionuclide type $s$ present per unit of mass of rock; the number of decays per unit of time is a straightforward function of the half-life of $s$. Radionuclide abundances are determined using measurements on chondritic meteorites. The initial amount (at $t=\mathrm{CAI}$ ) of long-lived radionuclides is determined through the present-day amount and their decay rate; the initial amount of short-lived radionuclides is a function of the present-day amount of the main stable isotope and canonical ratios: ${ }^{26} \mathrm{Al} /{ }^{27} \mathrm{Al}=5.23 \times 10^{-5}$ (Jacobsen et al. 2008) and ${ }^{60} \mathrm{Fe} /{ }^{56} \mathrm{Fe}=1.01 \times 10^{-8}$ (Tang \& Dauphas 2015).
While variability in the accreted ${ }^{26} \mathrm{Al} /{ }^{27} \mathrm{Al}$ ratio has been inferred from ${ }^{26} \mathrm{Al}-{ }^{26} \mathrm{Mg}$ systematics of primitive materials (Larsen et al. 2011; Nagashima et al. 2017), leading to lower ${ }^{26} \mathrm{Al}$ abundance in CI chondrites, this variability is contested (e.g., Kita et al. 2013). We use the canonical values to provide an upper limit on oxidant production. The abundance values obtained are presented in Table 1.

Ratio $\phi$. As defined in Sect. 2.1, Eq. (2), it is the ratio of the volume occupied by water to the total volume (water + rock). The initial water ice content of chondrite parent bodies is usually described using the water to rock ratio (W/R), either as a mass ratio or volume ratio. The value of $\phi$ can be directly derived from this value if one assumes a rock component density (value discussed below) and a liquid water density of $1.0 \mathrm{~g} \mathrm{~cm}^{-3}$.

On contemporary chondrites, in which the only water left is bound to the mineral structure, the measurement that is most closely connected to $\phi$ or W/R is porosity (volume of pore space divided by total volume). However the connection is not direct; the rocky component is aqueously altered, thus less dense, and simply assuming the pores are filled with water (i.e., considering $\phi=$ porosity) yields a W/R below the values inferred at accretion (Krot et al. 2015). As an example, the W/R of up to 1.2 (maximum derived from elemental solar ratios; Lodders 2003) inferred for CI, assuming a "dry" $\rho_{r}$ of $3.5 \mathrm{~g} \mathrm{~cm}^{-3}$, translates into a $\phi$ of 0.81 , considerably higher than the measured porosity of 0.35 in Orgueil (Macke et al. 2011). We also note that some of the pores seen in contemporary chondrites may have been filled with volatiles like $\mathrm{H}_{2}$ resulting from aqueous alteration (Rosenberg et al. 2001).

To bound our calculations, we adopt two end member cases: (1) the estimated W/R with $\rho_{r}=3.5 \mathrm{~g} \mathrm{~cm}^{-3}$ (dry rock case) to represent the situation at the onset of alteration more closely, and (2) contemporary values of $\rho_{r}$ (wet rock case) along with $\phi=$ measured porosity to represent the end of the alteration process. Below we elaborate on our choice of values to cover case 1).

- CI chondrites. We consider a maximum W/R (mass) of 1.2 , which is the highest value allowed by solar abundances (Lodders 2003) and leads to an extreme $\phi$ value of 0.81 . Maximum estimates are generally about three times lower. Brearley (2006) gives a W/R (mass) of 1.1-1.2, that Alexander (2019) converts into a $0.4-0.43 \mathrm{~W} / \mathrm{R}$ (mass). The analysis of Alexander (2019) supports a somewhat lower W/R (mass) of 0.38 (which would translate into $\phi=0.57$ ). We also consider a W/R value for CI material based on the data of the Rosetta mission on comet 67P/Churyumov-Gerasimenko (hereafter 67P/C-G). Comets, as relatively unprocessed bodies, may be more representative of the early solar system material that led to CI chondrites. We consider a $\mathrm{W} / \mathrm{R}$ value based on the dust-to-ice ratio measured in comet 67P/C-G; assuming a grain density of $3.5 \mathrm{~g} \mathrm{~cm}^{-3}$, the $4 \pm 2$ dust-to-ice mass ratio (Rotundi et al. 2015) translates into a $\phi$ value of $0.37-0.64$. By performing our calculations with $\phi=0.81$ (maximum W/R allowed by solar system abundances) and $\phi=0.37$ (lowest value for CI-like material suggested by the data acquired at comet $67 \mathrm{P} / \mathrm{C}-\mathrm{G}$ ) we cover the range of supported water content for the early solar system material that led to CI chondrites.

- CM chondrites. We consider the range proposed by Brearley (2006): W/R ( $\mathrm{vol})=0.3$ to 0.6 . This range is supported by the later analysis of Alexander (2019). It translates into $\phi=0.22$ to 0.36 .

- CV chondrites. The upper value of W/R (vol) suggested for the CV parent bodies is 1.1 (Brearley 2006) $(\phi=0.51)$, on par 
Table 1. Concentration of radionuclides used for the model (at CAI formation), and content in water, sulfur, and fraction of sulfur present as sulfates in contemporary carbonaceous chondrites.

\begin{tabular}{|c|c|c|c|c|c|c|c|c|c|}
\hline & ${ }^{40} \mathrm{~K}(\mathrm{ppb}){ }^{(a, b)}$ & ${ }^{232} \mathrm{Th}(\mathrm{ppb})^{(a, b)}$ & ${ }^{238} \mathrm{U}(\mathrm{ppb}){ }^{(a, b)}$ & ${ }^{235} \mathrm{U}(\mathrm{ppb}){ }^{(a, b)}$ & ${ }^{26} \mathrm{Al}(\mathrm{ppb}){ }^{(a, b)}$ & ${ }^{60} \mathrm{Fe}(\mathrm{ppb}){ }^{(a, b)}$ & Water wt $\%^{(c)}$ & Sulfur wt $\%^{(a)}$ & $f_{\mathrm{SO}_{4}}(\%)$ \\
\hline $\mathrm{CI}$ & $799-962$ & $36-43.7$ & $16.1-19.4$ & $5.1-6.1$ & $474-565$ & $1.93-2.29$ & 16.9 (Orgueil) & $5.41-6.51$ & $>39^{(d)}$ \\
\hline $\mathrm{CM}$ & $538-597.1$ & $51-57$ & $24.1-26.8$ & $7.6-8.5$ & $591-656$ & $2.15-2.39$ & 9.9 (avg) & $2.11( \pm 0.39)-2.34( \pm 0.43)^{(e)}$ & $>16^{(e, f)}$ \\
\hline $\mathrm{CV}$ & 523.5 & 72.6 & 34.2 & 10.8 & 879 & 2.37 & 0 & 2.7 & $0^{(g)}$ \\
\hline
\end{tabular}

Notes. When two values are displayed, the first value is a "wet" value (with respect to meteorites with their current water of hydration content), and the second is a "dry" value (removing the water content).

References. ${ }^{(a)}$ Lodders et al. (1998). ${ }^{(b)}$ Lodders (2003). ${ }^{(c)}$ Jarosewich (1990). ${ }^{(d)}$ Fredriksson \& Kerridge (1988); Burgess et al. (1991). ${ }^{(e)}$ Labidi et al. (2017). ${ }^{(f)}$ Alexander (2019). ${ }^{(g)}$ Brearley (2006).

Table 2. W/R, $\phi$ ratio, grain density, and accretion time used in the calculations above you use 67P/C-G; see also Fig. 1.

\begin{tabular}{|c|c|c|c|c|c|}
\hline & \multicolumn{2}{|c|}{ Estimated W/R } & \multicolumn{2}{|c|}{ Contemporary values ${ }^{(e)}$} & \multirow{2}{*}{$\begin{array}{c}\text { Accretion time post } \\
\text { CAI }(\mathrm{Myr})^{(f)}\end{array}$} \\
\hline & Initial W/R & $\phi$ & Grain density $\left(\mathrm{g} \mathrm{cm}^{-3}\right)$ & $\phi$ & \\
\hline CI & $1.2^{(a)}$ (mass) & 0.81 & 2.42 & 0.35 & 3.0 \\
\hline CI-67P & - & $0.36^{(b)}$ & - & - & 3.0 \\
\hline CM-Min & $0.3^{(c)}(\mathrm{vol})$ & 0.22 & 3.26 & 0.15 & 3.0 \\
\hline CM-Max & $0.6^{(c)}(\mathrm{vol})$ & 0.36 & 2.74 & 0.37 & 3.0 \\
\hline CV-Min & $0.09^{(d)}$ (mass) & 0.26 & 3.5 & 0.036 & 3.0 \\
\hline CV-Max & $1.1^{(c)}(\mathrm{vol})$ & 0.51 & 3.5 & 0.197 & 2.5 \\
\hline
\end{tabular}

References. ${ }^{(a)}$ Lodders (2003). ${ }^{(b)}$ Rotundi et al. (2015). ${ }^{(c)}$ Brearley (2006). ${ }^{(d)}$ Alexander (2019). ${ }^{(e)}$ Macke et al. $(2011) .{ }^{(f)}$ Doyle et al. $(2015)$; Desch et al. (2018).

with estimates for CI chondrites. We use this value as an upper limit, but it should be considered with caution; CV chondrites are believed to have undergone alteration at very low W/R (Krot et al. 2015). The model of Alexander (2019) yields a W/R (mass) of $0.09(\phi=0.26)$ to explain the bulk elemental and isotopic composition of $\mathrm{CV}$ chondrites. We use this value as the lower bound for our calculation.

Ratio of stopping powers. We use as a basis the values of $S_{i}^{\prime}$ considered in Bouquet et al. (2017), adapted to take into account the different $\rho_{r}$ when needed.

In summary, we consider two families of cases. The first uses estimated W/R at accretion and assumes $\rho_{r}=3.5 \mathrm{~g} \mathrm{~cm}^{-3}$. The second case considers contemporary chondrites, but with pores filled with water, based on measurement of their properties. The set of values considered is presented in Table 2.

Accretion time-onset of aqueous alteration. The amount of short-lived radionuclides decreases sharply on the timescale of a few million years after CAI formation; therefore, the time of onset of aqueous activity in the parent body, when liquid water is available for radiolysis, is a critical factor for the total production of oxidants. A later onset translates into a smaller cumulative production. To obtain an upper bound on this production, we consider aqueous alteration to start immediately after accretion, and we neglect the smaller amounts of $\mathrm{H}_{2} \mathrm{O}_{2}$ and $\mathrm{O}_{2}$ that are produced by endogenous radiolysis of the ice before it melts (Bouquet et al. 2018). The most commonly supported value for the accretion of the CI and CM parent bodies is 3.0 to $4.0 \mathrm{Myr}$ after CAI (see review of the literature in Desch et al. (2018); the estimates for CI and CM come mostly from Sugiura \& Fujiya (2014)). To obtain an upper limit on radiolytic production, we elect to consider the earliest time of accretion (when radionuclides are more abundant); therefore, we consider 3.0 Myr after CAI formation the nominal value for $\mathrm{CI}$ and $\mathrm{CM}$ chondrites. As far as CV chondrites are concerned, while $3.0 \mathrm{Myr}$ is also a supported accretion time, an earlier value of $2.5 \mathrm{Myr}$ after CAI may be considered for them (Doyle et al. 2015), which we include in the "maximum porosity" cases for an estimate of the upper bound of production (see the last column of Table 2).

Sulfur content. We seek to assess what fraction of the total sulfur present in the original material can be oxidized into sulfates by radiolytically produced oxidants. We consider a total initial amount of sulfur based on chondritic values (presented in Table 1 and covering all the forms of sulfur).

The output of our model is the fraction of the initial sulfur content converted into sulfates. We then compare this value to the fraction of sulfur present in sulfate form in carbonaceous chondrites; hereafter this quantity is denoted $f_{\mathrm{SO}_{4}}$. The study of Labidi et al. (2017) finds that $f_{\mathrm{SO}_{4}}=25 \%$ for CM chondrites; since they only recovered $64 \%$ of the bulk S, Alexander (2019) suggested decreasing this value to $f_{\mathrm{SO}_{4}}=16 \%$. In the case of CI chondrites, studies are in close agreement on the total sulfate content: $2.1-2.6 \mathrm{wt} \%$ for Orgueil (DuFresne \& Anders 1962; Boström \& Fredriksson 1966; Kaplan \& Hulston 1966; Monster et al. 1965; Fredriksson \& Kerridge 1988; Burgess et al. 1991). Depending on the estimate of total sulfur content, this can translate to very different $f_{\mathrm{SO}_{4}}$ values; Burgess et al. (1991) obtains a value of $74 \%$ for Orgueil, but from Fredriksson \& Kerridge (1988) we deduce $f_{\mathrm{SO}_{4}}=39 \%$, with their $\mathrm{S}$ total value being more in line with the general literature as reviewed by Lodders et al. (1998). The value of $f_{\mathrm{SO}_{4}}$ is not a parameter of our calculations, but matters for interpreting the results.

\section{Results}

The results of calculations based on initial W/R estimates are presented in Fig. 1, and those based on contemporary measured chondritic values in Fig. 2. The maximum sulfate production (as a fraction of the available sulfur) is reached for maximum W/R. 


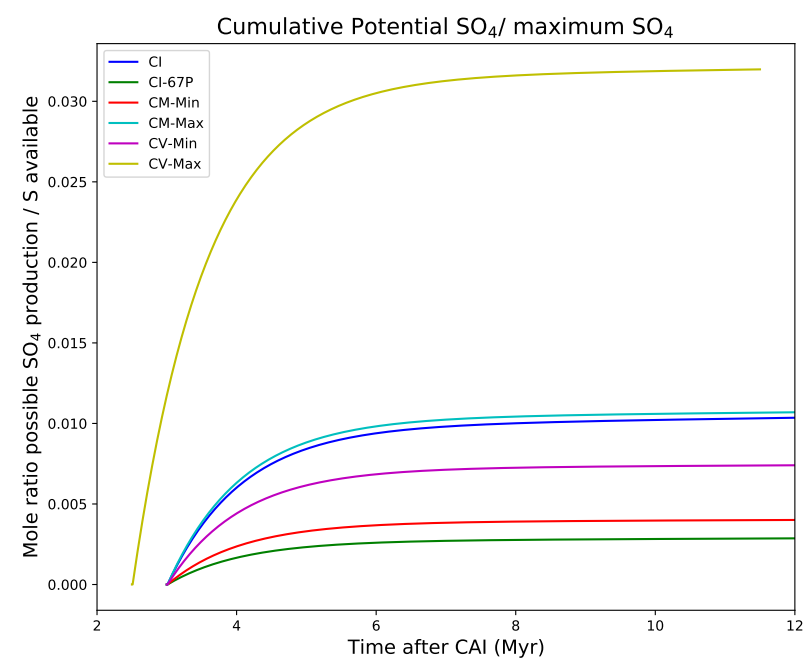

Fig. 1. Maximum fraction of sulfur that can be converted to sulfates through oxidation by radiolytically produced $\mathrm{OH}$ and $\mathrm{H}_{2} \mathrm{O}_{2}$, for each chondrite type, using an initial grain density of $3.5 \mathrm{~g} \mathrm{~cm}^{-3}$, assuming W/R values of 1.2 (CI), 0.4 (CI-67P), $0.1-0.6(\mathrm{CM})$, and $0.1-0.2$ $(\mathrm{CV})$. The $\mathrm{W} / \mathrm{R}=0.2$ case for $\mathrm{CV}$ was run assuming the earliest age of accretion of the parent body (CAI $+2.5 \mathrm{Myr})$ to obtain a maximum production; all other cases assume an accretion at CAI + 3.0 Myr (Doyle et al. 2015; Krot et al. 2015; Desch et al. 2018).

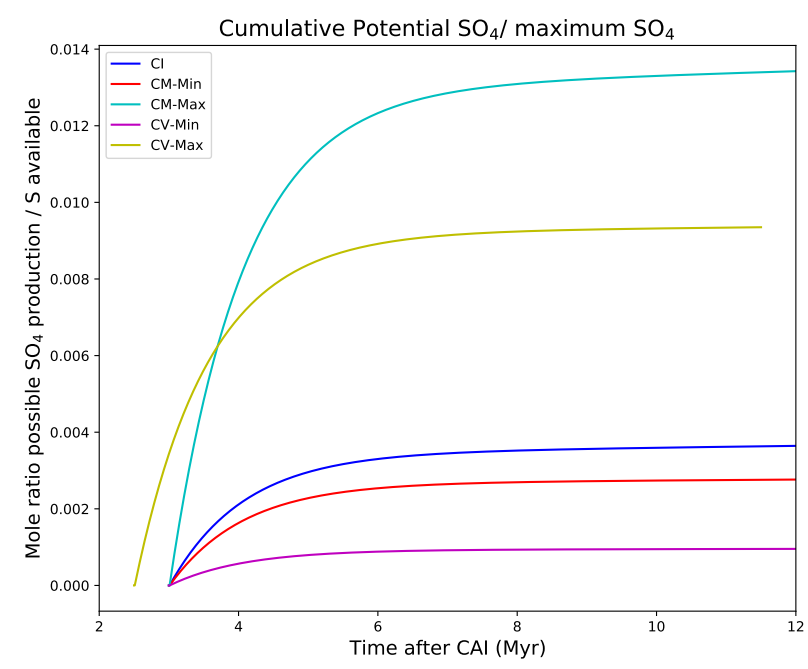

Fig. 2. Maximum fraction of sulfur that can be converted to sulfates through oxidation by radiolytically produced $\mathrm{OH}$ and $\mathrm{H}_{2} \mathrm{O}_{2}$, for each chondrite type, using contemporary (measured) values of grain density and porosity. All the pores are assumed to be filled with water in the parent body. The high-porosity case for $\mathrm{CV}$ was run assuming the earliest age of accretion of the parent body (CAI $+2.5 \mathrm{Myr})$ to obtain a maximum production; all other cases assume an accretion at CAI + 3.0 Myr (Doyle et al. 2015; Krot et al. 2015; Desch et al. 2018).

The amount of radiation emitted and the amount of available sulfur are intertwined (as both are tied to the rock component of the material) and higher W/R ensures most of the radiation energy is deposited into water and contributes to oxidant production. Therefore, the calculations based on the initial highest W/R estimates (Fig. 1) yield the larger sulfate production values.

It is apparent that none of the cases we have considered for CI and CM chondrites allow for a production that would explain the amount of sulfates observed in these chondrite types. At most $1.1 \%$ of the sulfur can be oxidized into sulfates for $\mathrm{CM}$, assuming the most favorable case (lowest sulfur content, highest $\mathrm{W} / \mathrm{R}$ ): this would form less than $5 \%$ of the observed sulfates. The relatively flat profile of the cumulative production more than $6 \mathrm{Myr}$ after CAI formation shows that the production due to long-lived radionuclides is negligible compared to the production induced by short-lived radionuclides. Considering a longer or shorter (but still $>2 \mathrm{Myr}$ ) duration of aqueous alteration therefore does not change our results significantly. In the CI case, no more than $1.1 \%$ of the available sulfur can be converted into sulfates, an amount considerably lower than even the lowest estimate $\left(f_{\mathrm{SO}_{4}}=39 \%\right)$ discussed earlier. Early onset of aqueous alteration, which we considered in the CV case (2.5 Myr instead of $3 \mathrm{Myr}$ ) drastically increases production of oxidants compared to the nominal onset time. Even so, no more than $3.2 \%$ of the sulfur content of CVs can be oxidized into sulfate this way. We further explored the effect of an early onset of alteration (calculations not displayed), and find it is possible for the CM chondrites to match the observed $16 \% f_{\mathrm{SO}_{4}}$ if the alteration starts at $0.1 \mathrm{Myr}$ after CAI, an unrealistically early time (Jilly et al. 2014).

\section{Discussion}

\subsection{The role of endogenous radiolysis}

Our estimates of sulfate production constitute an upper bound as they assume that all the radiolytically produced oxidants are consumed in the production of sulfates, without taking into account other sinks for these oxidants (such as oxidation of reduced forms of iron or organic materials). We find that the radiolytic oxidants are not sufficient to explain a significant fraction of the observed sulfates in CM chondrites. If a significant part of the sulfates in CI meteorites is assumed to be extraterrestrial in origin (as opposed to being produced by oxidation while in curation), the same conclusion holds: radiolytic production can only contribute a minor amount compared to what is observed. Our calculations for $\mathrm{CV}$ chondrites result in an amount of sulfate representing between $0.1 \%$ and $3.3 \%$ of the total sulfur (by mole). Since no sulfate has been reported in CV meteoritic samples (Brearley 2006), it is likely that the set of assumptions leading to the lowest sulfate production (i.e., low water content and late aqueous alteration) is the closest to reality. High temperatures experienced by $\mathrm{CV}$ chondrites have also been proposed as a cause for the reduction of potential sulfates to sulfides or elemental sulfur (Bose et al. 2017).

\subsection{Effect of accreted $\mathrm{O}_{2}$}

We consider the possibility of oxidation of sulfur-bearing minerals (to include sulfides and all S-bearing phases; hereafter sulfur) by $\mathrm{O}_{2}$ contained in accreted ice. This possibility is debatable depending on the type of CC considered. The parallel between CI chondrites and cometary bodies (specifically, between Jupiterfamily comets and Orgueil) has been made before through trajectory calculation (Gounelle et al. 2006). However, the differences in isotopic ratios (see discussion below) between CI chondrites and comets point to different reservoirs and formation conditions, so this possibility should be considered cautiously. It is difficult to retain $\mathrm{O}_{2}$, a very volatile species, in solid phase in large amounts. The inferred zone of formation of CI chondrites has been estimated to be as far as $15 \mathrm{AU}$ (Desch et al. 2018) at a temperature of $46 \mathrm{~K}$ at $3 \mathrm{Myr}$ after CAI. This temperature, within the range of pressures expected in the disk, would not allow pure $\mathrm{O}_{2}$ condensation, but a CO-dominated clathrate including $\mathrm{O}_{2}$ can remain stable (Mousis et al. 2016), as can a pure $\mathrm{O}_{2}$ clathrate (calculation based on constants given in 


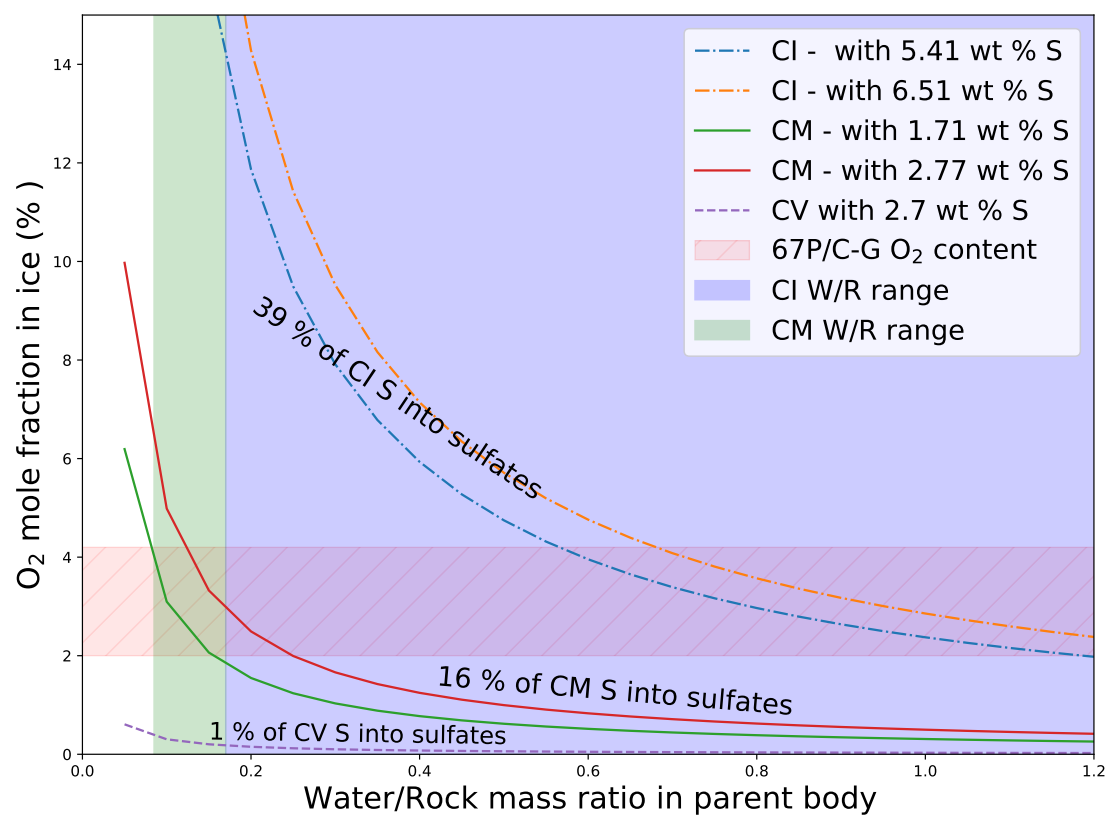

Fig. 3. Mole fraction of $\mathrm{O}_{2}$ in accreted ice vs the W/R ratio assumed in the parent body. The plots show, for a given W/R, how much accreted $\mathrm{O}_{2}$ is necessary to oxidize enough of the total sulfur content into a quantity of sulfates consistent with contemporary measurements (see last two columns of Table 1: $16 \%$ for the CM case, 39\% for the CI case). The green part of the diagram covers the estimated range of W/R in CM parent bodies, the blue part covers the estimated W/R for CI parent bodies. The CV curve corresponds to the quantity of $\mathrm{O}_{2}$ that would lead to the oxidation of $1 \%$ of sulfur into sulfates. The red overlay represents the range of $\mathrm{O}_{2}$ abundance in the ice of comet $67 \mathrm{P} / \mathrm{C}-\mathrm{G}(3.1 \pm 1.1 \%)$ as observed by the Rosetta mission (Rubin et al. 2019).

Kuhs et al. 2000). Another possibility is that mixing within the disk allowed materials that formed in the outer, colder section of the disk to be included in the formation of CC parent bodies. To retain at least a part of their molecular oxygen, these materials should be included in planetesimals large enough (kilometer size or more) to not equilibrate with the disk within the time frame of their migration and inclusion in CC parent bodies. In the case of $\mathrm{CM}$ chondrites, this is the most likely way to include $\mathrm{O}_{2}$ since either pure $\mathrm{O}_{2}$ ice or clathrate would be unstable at the inferred range of forming temperature of $\mathrm{CM}$ parent bodies, about $100 \mathrm{~K}$ (Desch et al. 2018).

We calculate, as a function of W/R, how much $\mathrm{O}_{2}$ in the ice is necessary to oxidize a target fraction of sulfur into sulfates $(39 \%$ for CI, 25\% for CM; see Table 1). This assumes that all the $\mathrm{O}_{2}$ thus accreted goes toward the oxidation of sulfur. For CI and CM, this calculation is performed for their minimum and maximum sulfur content (see Table 1; the calculation results are displayed in Fig. 3). We display the $\mathrm{O}_{2}$ content of comet $67 \mathrm{P} / \mathrm{C}-\mathrm{G}$, with the $3.1 \pm 1.1 \%$ of $\mathrm{O}_{2}$ (by number with respect to water) identified by the ROSINA mass spectrometer aboard the Rosetta mission (Bieler et al. 2015; Rubin et al. 2019), as a reference range for the possible $\mathrm{O}_{2}$ abundance in ice representative of the early solar system. Other measurements by the ALICE far-UV spectrograph also on board the Rosetta mission point toward a much higher $\mathrm{O}_{2} / \mathrm{H}_{2} \mathrm{O}$ value, typically on the order of $50 \%$ (Feldman et al. 2016). However, this value is linked to outburst events, so the ROSINA values are more likely to represent the bulk $\mathrm{O}_{2} / \mathrm{H}_{2} \mathrm{O}$ of the comet. Since sulfates are not observed in $\mathrm{CV}$ chondrites, we plot a curve with an arbitrary target sulfate fraction of $1 \%$ as a possible upper limit for the amount of $\mathrm{O}_{2}$ present in the ice accreted by $\mathrm{CV}$ parent bodies.

In the case of CI chondrites, Fig. 3 indicates that with W/R values within the upper range of estimates (W/R(mass) $>0.6$ ), an $\mathrm{O}_{2}$ content comparable to the one measured in $67 \mathrm{P} / \mathrm{C}-\mathrm{G}$ by the ROSINA instrument, allows for the production of a large amount of sulfates. These numbers are compatible with accreted $\mathrm{O}_{2}$ playing a key role in forming sulfates in the CI chondrites parent body.

Calculations with values pertaining to $\mathrm{CM}$ chondrites similarly indicate that with $\mathrm{W} / \mathrm{R}$ values compatible with literature estimates (0.3-0.6 per volume, Brearley 2006, translated into 0.09 to 0.17 per mass), it is possible their parent body accreted enough $\mathrm{O}_{2}$ to create the amount of sulfates observed now. However, the ice mixture accreted by CM parent bodies was likely not entirely unprocessed, and therefore had lost part of its most volatile compounds, which would include $\mathrm{O}_{2}$ devolatilized (Marrocchi et al. 2018). Alexander et al. (2017) propose that only $5-10 \%$ of the material would be pristine interstellar material. When considering this amount of volatile-rich ice mixture (with an $\mathrm{O}_{2}$ content comparable to comet 67P/C-G), and assuming that the rest is devoid of species more volatile than water, there would not be sufficient $\mathrm{O}_{2}$ to oxidize enough sulfur into sulfates to match the observations. This would require a much higher content of $\mathrm{O}_{2}$ in the pristine portion of the accreted ice; we calculate that the $\mathrm{O}_{2}$ content of the $10 \%$ of pristine material should be $35 \%$ for a $0.6 \mathrm{~W} / \mathrm{R}$ (volume) ratio. On the other hand, this number is still below the $\mathrm{O}_{2} / \mathrm{H}_{2} \mathrm{O}$ ratio measured by the ALICE far-UV spectrograph in the coma of comet $67 \mathrm{P} / \mathrm{C}-\mathrm{G}$. However, there is no known chemical scheme that can explain such a high $\mathrm{O}_{2}$ abundance in the protosolar nebula.

The calculation for $\mathrm{CV}$ chondrites indicates that a low $\mathrm{O}_{2}$ content $\left(\mathrm{O}_{2} / \mathrm{H}_{2} \mathrm{O}<0.3 \%\right.$ by numbers $)$ is required to limit the amount of sulfate formed, which is compatible with $\mathrm{CV}$ parent bodies forming closer to the Sun and accreting an ice mixture poor in the most volatile molecules, and in smaller quantity (Marrocchi et al. 2018).

We note, however, that none of our calculations takes into account any possible competition for oxidants (see discussion in Sect. 2.1). This competition would partly depend on the $\mathrm{pH}$ and the fate of $\mathrm{Fe}^{2+}$ ions. Considering a scenario where the aqueous alteration comes from the melting of cometary-like ices, could the $\mathrm{pH}$ be initially acidic before rock-water interaction drives 
it toward alkaline values? We calculated the $\mathrm{pH}$ of an aqueous solution resulting from melting an ice with the volatile composition of comet $67 \mathrm{P} / \mathrm{C}-\mathrm{G}$, as assessed by the ROSINA instrument (Rubin et al. 2019). We considered species that can participate in acid-base chemistry, using the SpecE8 app of the Geochemist Workbench 2021 software with the thermo.com.V8.R6+ database. No mineral or redox reactions were included and the temperature is assumed to be $25^{\circ} \mathrm{C}$. The species that could be taken into account include $\mathrm{H}_{2} \mathrm{O}, \mathrm{CO}_{2}, \mathrm{HCOOH}, \mathrm{CH}_{3} \mathrm{COOH}$, $\mathrm{NH}_{3}, \mathrm{HCN}, \mathrm{H}_{2} \mathrm{~S}, \mathrm{SO}_{2}, \mathrm{HF}, \mathrm{HCl}$, and $\mathrm{HBr}$; the species that were not included for lack of thermodynamic data all have abundances below $0.1 \%$. The abundances of the species considered and the Geochemist Workbench outputs can be found in Appendix A. We find that the $\mathrm{pH}$ of this mixture is mildly acidic $(\sim 5) . \mathrm{NH}_{3}$ plays a large role in limiting the acidity; a calculation without $\mathrm{NH}_{3}$ yields a $\mathrm{pH}$ below 2 . Calculations with only halide acids and only $\mathrm{CO}_{2}$ yield $\mathrm{pH}$ values of 2 and 3, respectively. Halide acids, mainly $\mathrm{HCl}$, (Zolotov \& Mironenko 2007) appear as the main drivers of the acidification of the solution. This indicates that variations in the amount of $\mathrm{NH}_{3}$ accreted may have allowed an initially acidic solution, letting $\mathrm{Fe}^{3+}$ act as an oxidizer of pyrrhotite in the early stages of alteration.

We now consider whether isotopic evidence matches the hypothesis of sulfate formation from accreted $\mathrm{O}_{2}$. The oxidation of sulfides into sulfates by $\mathrm{O}_{2}$ in aqueous solution is known to favor ${ }^{32} \mathrm{~S}$ (Fry et al. 1988; Eldridge \& Farquhar 2018), consistent with the depletion in heavy $\mathrm{S}$ isotopes in chondritic sulfates compared to sulfides (Gao \& Thiemens 1993; Labidi et al. 2017). Isotope exchanges of ${ }^{18} \mathrm{O}$ between sulfates and water are kinetically inhibited in most conditions (Lloyd 1968; Chiba \& Sakai 1985; Van Stempvoort \& Krouse 1994), but the fastest exchange rates observed would still allow equilibration in $10^{3}$ to $10^{5}$ year (Lloyd 1968). This is well within the time frame of aqueous alteration in CC parent bodies, where hotter temperatures may also have promoted faster equilibration. Exchanges between $\mathrm{H}_{2} \mathrm{O}$ and $\mathrm{SO}_{3}^{-2}$, which Lloyd (1968) proposes as an intermediate in sulfate production, are also found to be much faster (on a timescale of hours). The likely outcome is that $\delta^{18} \mathrm{O}$ in sulfates would mostly be a function of the $\delta^{18} \mathrm{O}$ of the water present. Another factor is that even in the presence of $\mathrm{O}_{2}$ the sulfates resulting from oxidation of sulfides derive their oxygen mostly (but variably) from water rather than $\mathrm{O}_{2}$ (Taylor et al. 1984; Toran \& Harris 1989; Balci et al. 2007). Isotopic equilibrium between sulfate and water favors the integration of ${ }^{18} \mathrm{O}$ in sulfates (Lloyd 1968) to a varying degree depending on the experimental conditions. This is true for dissolved sulfates and minerals.

Isotopic ratios in cometary oxygen (in water and in molecular oxygen) are available only for comet $67 \mathrm{P} / \mathrm{C}-\mathrm{G}$. The measured ${ }^{16} \mathrm{O} /{ }^{18} \mathrm{O}=345 \pm 40$ for $\mathrm{O}_{2}$ shows a very significant enrichment in ${ }^{18} \mathrm{O}$ (Altwegg et al. 2020) compared to the terrestrial values, leading to $\delta^{18} \mathrm{O}=+295$ to $+635 \%$. Even with the rather low fraction of sulfate oxygen coming from $\mathrm{O}_{2}$, such a high value would likely be reflected in the sulfates before isotopic exchanges with water. The water ice of comet 67P/C-G also seems rich in heavy isotopes (Schroeder et al. 2019) with $\delta^{18} \mathrm{O}$ between 39 to $216 \%$ o. However the large error bars on this value make it statistically compatible, within $1.5 \sigma$, with terrestrial values; therefore, no firm constraint can be derived from it.

CI chondrite sulfates are impoverished in ${ }^{18} \mathrm{O}$ compared to the bulk oxygen: $\delta^{18} \mathrm{O}_{\text {sulfates }}=+4.8 \%$ (Ivuna) and $+5.4 \%$ o (Orgueil) (Airieau et al. 2005) versus a bulk $\delta^{18} \mathrm{O}$ of $+16 \%$ o (Clayton \& Mayeda 1999). If sulfates were the products of oxidation driven by $\mathrm{O}_{2}$, and possibly had isotopically equilibrated with water (presumably more ${ }^{18} \mathrm{O}$-rich than the bulk $\mathrm{O}$ content), their $\delta^{18} \mathrm{O}$ value should be larger than the bulk. Along with the $\Delta \Delta^{17} \mathrm{O}$ of $\mathrm{CI}$ sulfates (sitting on the terrestrial fractionation line) this could support a terrestrial origin of these sulfates.

CM chondrites show a less marked trend (Clayton \& Mayeda 1999; Airieau et al. 2005), with $\delta^{18} \mathrm{O}_{\text {sulfates }}=+9.5 \%$, compared to bulk values between 5 and $12 \%$. The primordial water in CM chondrite parent bodies has been inferred by Fujiya (2018) at $\delta^{18} \mathrm{O}=55 \pm 13 \%$ o, compatible with the range found in previous studies (Alexander et al. 2015; Guo \& Eiler 2007). A scenario of production of sulfate by $\mathrm{O}_{2}$-driven oxidation is compatible with these values, if we consider that the lower end of the bulk $\delta^{18} \mathrm{O}$ value range represents the $\delta^{18} \mathrm{O}$ of water at the end of the alteration process, and that sulfates isotopically equilibrated with water at this late stage.

\subsection{Conclusion}

We showed that for a variety of scenarios, endogenous radiolysis can only deliver a very small contribution to the oxidation of the parent bodies of carbonaceous chondrites, as indicated by the very modest amount of sulfates that could be created through this process. Variation of key parameters such as the W/R ratio or the time for starting aqueous alteration cannot raise this contribution to a significant level unless some unrealistic values are assumed. Recent experimental evidence using Earth sediments indicates radiolysis yields may be considerably larger than those used in the present work (Sauvage et al. 2021). Considering the maximum enhanced yields, the oxidant production by endogenous radiolysis may become a larger contributor to sulfate formation (up to $11 \%$ of sulfur can be converted into sulfates in the CM case; see Appendix B) and generally to the evolution of the parent body redox state. However, this effect is highly dependent on the type of sediment considered, and its applicability to early CC parent bodies is not straightforward. Sauvage et al. (2021) suggest the catalytic effect might be due to zeolites, which to our knowledge are not expected in CC parent bodies, and calcite, which is present in CC chondrites. Experiments using the protocol of Sauvage et al. (2021) with chondritic materials would be needed to clarify this question. In the meantime, endogenous radiolysis should be considered a likely minor contributor. By contrast, solid $\mathrm{O}_{2}$ accreted with ice could account for a large proportion or even all of the sulfates formed on the parent body. The pre-accretionary origin of $\mathrm{O}_{2}$ in comet $67 \mathrm{P} / \mathrm{C}-\mathrm{G}$ is one of the best supported scenarios to date (Mousis et al. 2016; Taquet et al. 2016, 2017; Luspay-Kuti et al. 2018; Altwegg et al. 2020), allowing for its presence in ice accreted by the CC parent bodies. However, experimental evidence and reaction pathways indicate that this process would have also likely produced large amounts of elemental sulfur, but CC chondrites possess only minor amounts of it.

In the asteroid main belt, Ceres presents an interesting case of a body having undergone extensive aqueous alteration with a very high W/R ratio (Castillo-Rogez et al. 2019) that could have hosted the production of sulfates. Sulfate salts are expected to be mobile, and salt deposits on the surface would give insights into the interior. However, sulfates have not yet been firmly identified in the recent deposits of aqueously altered material on the surface of Ceres, nor can their presence be excluded (Hendrix et al. 2016; Bu et al. 2018). Modeling studies regarding Ceres indicate their formation to be highly model dependent (Neveu et al. 2017; Castillo-Rogez et al. 2018). A future mission to Ceres might be able to test for sulfates on the surface and to inform further interpretations about the process of sulfate formation in $\mathrm{CC}$ parent bodies. The sample return from asteroid Bennu by the 
OSIRIS-REx (Lauretta et al. 2017) mission may allow further exploration of this question. Bennu was chosen as the mission target for its spectral similarity to $\mathrm{CC}$ meteorites, and observations by the spacecraft have confirmed the presence of aqueously altered material (Kaplan et al. 2020). The presence and amount (or absence) of sulfates in the sample to be returned will offer new insights to interpret the available data on chondrites, in particular regarding whether sulfates in CI chondrites find their origin in terrestrial alteration.

Acknowledgements. A.B. and O.M. acknowledge support by CNES. C.R.G. and K.E.M. acknowledge support from SwRI. Figures drawn with Matplotlib (Hunter 2007).

\section{References}

Airieau, S., Farquhar, J., Thiemens, M., et al. 2005, Geochim. Cosmochim. Acta, 69,4167

Alexander, C. M. 2019, Geochim. Cosmochim. Acta, 254, 277

Alexander, C. O., Bowden, R., Fogel, M., \& Howard, K. 2015, Meteor. Planet. Sci., 50, 810

Alexander, C. M. O., Nittler, L. R., Davidson, J., \& Ciesla, F. J. 2017, Meteor. Planet. Sci., 52, 1797

Altwegg, K., Balsiger, H., Combi, M., et al. 2020, MNRAS, 498, 5855

Baikova, I., Shtamm, E., Vichutinskaya, E., \& Skurlatov, Y. I. 2009, Russ. J. Phys. Chem. B, 3, 251

Balci, N., Shanks III, W. C., Mayer, B., \& Mandernack, K. W. 2007, Geochim. Cosmochim. Acta, 71, 3796

Belzile, N., Goldsack, D., Maki, S., \& McDonald, A. 1997, in Environmental Geology of Urban Areas (Geological Association of Canada St. John's, Canada), 223

Belzile, N., Chen, Y.-W., Cai, M.-F., \& Li, Y. 2004, J. Geochem. Explor., 84, 65 Bieler, A., Altwegg, K., Balsiger, H., et al. 2015, Nature, 526, 678

Blair, C. C., D’Hondt, S., Spivack, A. J., \& Kingsley, R. H. 2007, Astrobiology, 7,951

Bland, P. A., Cressey, G., \& Menzies, O. N. 2004, Meteor. Planet. Sci., 39, 3

Bose, M., Root, R., \& Pizzarello, S. 2017, Meteor. Planet. Sci., 52, 546

Boström, K., \& Fredriksson, K. 1966, Smithsonian Miscellaneous Collections

Bouquet, A., Glein, C. R., Wyrick, D., \& Waite, J. H. 2017, ApJ, 840, L8

Bouquet, A., Mousis, O., Teolis, B., et al. 2018, ApJ, 864, 9

Brearley, A. J. 2006, Meteor. Early Solar Syst. II, 943, 587

Brearley, A., \& Jones, C. 1998, "Chondritic meteorites", in Planetary materials, ed J. Papike, 36 (Mineralogical Society of America)

Bu, C., Rodriguez Lopez, G., Dukes, C., et al. 2018, Meteor. Planet. Sci., 53, 1946

Buckley, A., , \& Woods, R. 1985, Appl. Surf. Sci., 22, 280

Bullock, E. S., McKeegan, K. D., Gounelle, M., Grady, M. M., \& Russell, S. S. 2010, Meteor. Planet. Sci., 45, 885

Burgess, R., Wright, I., \& Pillinger, C. 1991, Meteoritics, 26, 55

Castillo-Rogez, J., Neveu, M., McSween, H. Y., et al. 2018, Meteor. Planet. Sci., 53, 1820

Castillo-Rogez, J. C., Hesse, M., Formisano, M., et al. 2019, Geophys. Res. Lett., 46, 1963

Chiba, H., \& Sakai, H. 1985, Geochim. Cosmochim. Acta, 49, 993

Chiriță, P., \& Descostes, M. 2006, J. Colloid Interface Sci., 299, 260

Clayton, R. N., \& Mayeda, T. K. 1999, Geochim. Cosmochim. Acta, 63, 2089

Cody, G. D., \& Alexander, C. M. 2005, Geochim. Cosmochim. Acta, 69, 1085

Desch, S. J., Kalyaan, A., \& Alexander, C. M. 2018, ApJS, 238, 11

Donaldson Hanna, K., Schrader, D., Cloutis, E., et al. 2019, Icarus, 319, 701

Doyle, P. M., Jogo, K., Nagashima, K., et al. 2015, Nat. Commun., 6, 7444

Dreibus, G., Palme, H., Spettel, B., Zipfel, J., \& Wänke, H. 1995, Meteoritics, 30,439

DuFresne, E. R., \& Anders, E. 1962, Geochim. Cosmochim. Acta, 26, 1085

Dzaugis, M., Spivack, A. J., \& D'Hondt, S. 2018, Astrobiology

Eldridge, D. L., \& Farquhar, J. 2018, Geochim. Cosmochim. Acta, 237, 240

Feldman, P. D., A'hearn, M. F., Feaga, L. M., et al. 2016, ApJ, 825, L8

Fredriksson, K., \& Kerridge, J. F. 1988, Meteoritics, 23, 35

Fry, B., Ruf, W., Gest, H., \& Hayes, J. 1988, Chem. Geol.: Isotope Geosci. Sect., 73,205

Fujiya, W. 2018, Earth Planet. Sci. Lett., 481, 264

Gao, X., \& Thiemens, M. H. 1993, Geochim. Cosmochim. Acta, 57, 3159

Gounelle, M., \& Zolensky, M. E. 2001, Meteor. Planet. Sci., 36, 1321

Gounelle, M., Spurnỳ, P., \& Bland, P. A. 2006, Meteor. Planet. Sci., 41, 135

Guo, W., \& Eiler, J. M. 2007, Geochim. Cosmochim. Acta, 71, 5565

Hamilton, I., \& Woods, R. 1981, J. Electroanal. Chem. Interfacial Electrochem., 118,327

Hendrix, A. R., Vilas, F., \& Li, J.-Y. 2016, Geophys. Res. Lett., 43, 8920
Hoffman, B. 1992, in Proceedings of the 7th International Symposium on WaterRock Interaction, 503

Hua, X., \& Buseck, P. R. 1998, Meteor. Planet. Sci., 33, A215

Hunter, J. D. 2007, Comput. Sci. Eng., 9, 90

Huss, G. R., Rubin, A. E., \& Grossman, J. N. 2006, Meteor. Early Solar Syst. II, 943,567

Hyman, M., \& Rowe, M. 1983, J. Geophys. Res.: Solid Earth, 88, A736

Jacobsen, B., Yin, Q.-Z., Moynier, F., et al. 2008, Earth Planet. Sci. Lett., 272, 353

Janzen, M. P., Nicholson, R. V., \& Scharer, J. M. 2000, Geochim. Cosmochim. Acta, 64, 1511

Jarosewich, E. 1990, Meteoritics, 25, 323

Jilly, C. E., Huss, G. R., Krot, A. N., et al. 2014, Meteor. Planet. Sci., 49, 2104

Jones, C. L., \& Brearley, A. J. 2006, Geochim. Cosmochim. Acta, 70, 1040

Kaplan, I. R., \& Hulston, J. R. 1966, Geochim. Cosmochim. Acta, 30, 479

Kaplan, H., Lauretta, D., Simon, A., et al. 2020, Science, 370

King, A., Schofield, P., Howard, K., \& Russell, S. 2015, Geochim. Cosmochim. Acta, 165,148

Kita, N. T., Yin, Q.-Z., MacPherson, G. J., et al. 2013, Meteor. Planet. Sci., 48, 1383

Krot, A., Nagashima, K., Alexander, C., et al. 2015, Asteroids IV, 635

Kuhs, W. F., Klapproth, A., \& Chazallon, B. 2000, in Physics of Ice Core Records (Hokkaido University Press), 373

Labidi, J., Farquhar, J., Alexander, C. O., Eldridge, D., \& Oduro, H. 2017, Geochim. Cosmochim. Acta, 196, 326

Larsen, K. K., Trinquier, A., Paton, C., et al. 2011, ApJ, 735, L37

Lauretta, D., Balram-Knutson, S., Beshore, E., et al. 2017, Space Sci. Rev., 212, 925

Lefticariu, L., Pratt, L. A., LaVerne, J. A., \& Schimmelmann, A. 2010, Earth Planet. Sci. Lett., 292, 57

Lewis, J. S. 1967, Earth Planet. Sci. Lett., 2, 29

Li, L., Wing, B., Bui, T., et al. 2016, Nat. Commun., 7, 13252

Lin, L.-H., Hall, J., Lippmann-Pipke, J., et al. 2005a, Geochem. Geophys. Geosyst., 6

Lin, L.-H., Slater, G. F., Lollar, B. S., Lacrampe-Couloume, G., \& Onstott, T. 2005b, Geochim. Cosmochim. Acta, 69, 893

Lloyd, R. 1968, J. Geophys. Res., 73, 6099

Lodders, K. 2003, ApJ, 591, 1220

Lodders, K., Fegley, B., Lodders, F., et al. 1998, The Planetary Scientist's Companion (Oxford University Press on Demand)

Luspay-Kuti, A., Mousis, O., Lunine, J. I., et al. 2018, Space Sci. Rev., 214, 115

Macke, R. J., Consolmagno, G. J., \& Britt, D. T. 2011, Meteor. Planet. Sci., 46, 1842

Marrocchi, Y., Bekaert, D. V., \& Piani, L. 2018, Earth Planet. Sci. Lett., 482, 23

Monster, J., Anders, E., \& Thode, H. 1965, Geochim. Cosmochim. Acta, 29, 773

Moore, M., Hudson, R., \& Carlson, R. 2007, Icarus, 189, 409

Mousis, O., Ronnet, T., Brugger, B., et al. 2016, ApJ, 823, L41

Nagashima, K., Krot, A. N., \& Komatsu, M. 2017, Geochim. Cosmochim. Acta, 201, 303

Neveu, M., Desch, S. J., \& Castillo-Rogez, J. C. 2017, Geochim. Cosmochim. Acta, 212, 324

Oana, S., \& Ishikawa, H. 1966, Geochem. J., 1, 45

Ohmoto, H., \& Lasaga, A. C. 1982, Geochim. Cosmochim. Acta, 46, 1727

Ray, C., Glein, C. R., Waite, J. H., et al. 2021, Icarus, 114248

Rosenberg, N. D., Browning, L., \& Bourcier, W. L. 2001, Meteor. Planet. Sci., 36,239

Rotundi, A., Sierks, H., Della Corte, V., et al. 2015, Science, 347, aaa3905

Rubin, M., Altwegg, K., Balsiger, H., et al. 2019, MNRAS, 489, 594

Sauvage, J. F., Flinders, A., Spivack, A. J., et al. 2021, Nat. Comm., 12, 1

Schroeder, I. R., Altwegg, K., Balsiger, H., et al. 2019, A\&A, 630, A29

Sherwood Lollar, B., Onstott, T., Lacrampe-Couloume, G., \& Ballentine, C. 2014, Nature, 516, 379

Spinks, J. W. T., \& Woods, R. J. 1990, An introduction to radiation chemistry (New York, NY, USA: John Wiley and Sons Inc)

Sugiura, N., \& Fujiya, W. 2014, Meteor. Planet. Sci., 49, 772

Tang, H., \& Dauphas, N. 2015, ApJ, 802, 22

Taquet, V., Furuya, K., Walsh, C., \& van Dishoeck, E. F. 2016, MNRAS, 462, S99

Taquet, V., Furuya, K., Walsh, C., \& van Dishoeck, E. F. 2017, Proc. Int. Astron. Union, 13, 187

Taylor, B. E., Wheeler, M. C., \& Nordstrom, D. K. 1984, Geochim. Cosmochim. Acta, 48, 2669

Toran, L., \& Harris, R. F. 1989, Geochim. Cosmochim. Acta, 53, 2341

Van Stempvoort, D., \& Krouse, H. 1994, Environmental Geochemistry of Sulfide Oxidation (ACS Publications), 446

Zolensky, M. E., Bourcier, W. L., \& Gooding, J. L. 1989, Icarus, 78, 411

Zolotov, M. Y., \& Mironenko, M. 2007, in Lunar and Planetary Science Conference No. 1338, 2340 
A. Bouquet et al.: Endogenous radiolysis in chondritic bodies

\section{Appendix A: The Geochemist's Workbench calculation inputs}

We detail in Table A.1 the volatile composition we used to assess the $\mathrm{pH}$ of a melt of cometary ices, based on measurements by the Rosetta mission at comet $67 \mathrm{P} / \mathrm{C}-\mathrm{G}$.

The input of the GWB calculations are detailed below.
Table A.1. Composition of cometary ices used as reference in the $\mathrm{pH}$ calculation of Sect. 4.2, based on Rubin et al. (2019).

\begin{tabular}{ccc}
\hline \hline Species & Moles & Molality \\
\hline $\mathrm{H}_{2} \mathrm{O}$ & 100 & 55.56 \\
$\mathrm{CO}_{2}$ & 4.7 & 2.61 \\
$\mathrm{HCOOH}$ & 0.013 & 0.0072 \\
$\mathrm{CH}_{3} \mathrm{COOH}$ & 0.0034 & 0.0019 \\
$\mathrm{NH}_{3}$ & 0.67 & 0.3722 \\
$\mathrm{HCN}^{(*)}$ & 0.14 & 0.0778 \\
$\mathrm{HNCO}^{(*)}$ & 0.027 & 0.015 \\
$\mathrm{H}_{2} \mathrm{~S}^{(*)}$ & 1.1 & 0.6111 \\
$\mathrm{OCS}^{(*)}$ & 0.041 & 0.0228 \\
$\mathrm{SO}_{2}$ & 0.127 & 0.0706 \\
$\mathrm{CS}_{2}{ }^{(*)}$ & 0.0057 & 0.0032 \\
$\mathrm{H}_{2} \mathrm{CS}^{(*)}$ & 0.0027 & 0.0015 \\
$\mathrm{CH}_{3} \mathrm{SH}^{(*)}$ & 0.038 & 0.0211 \\
$\mathrm{HF}$ & 0.011 & 0.0061 \\
$\mathrm{HCl}$ & 0.014 & 0.0078 \\
\hline
\end{tabular}

Notes. Species flagged with an asterisk ${ }^{(*)}$ are absent from the thermodynamic database (thermo.com.V8.R6+), and are therefore not included in the calculations. 
Acid-base equilibrium of melted ices from comet 67P. No redox reactions allowed.

\begin{tabular}{|c|c|c|}
\hline $\begin{array}{l}\text { Temperature }=25.0 \\
\mathrm{pH}=5.233\end{array}$ & Pressure & $=1.013 \mathrm{bar}$ \\
\hline Ionic strength & 0.373845 & molal \\
\hline Activity of water & 0.999728 & \\
\hline Solvent mass & 1.0000 & $\mathrm{~kg}$ \\
\hline Solution mass & 1.1555 & $\mathrm{~kg}$ \\
\hline Mineral mass & 0.0000 & $\mathrm{~kg}$ \\
\hline Fluid density & 1.093 & $\mathrm{~g} / \mathrm{cm} 3$ \\
\hline compressibility & $3.821 \mathrm{e}-05$ & /bar \\
\hline expansivity & 0.0002477 & /C \\
\hline viscosity & 0.009 & poise \\
\hline Chlorinity & 0.007778 & molal \\
\hline Dissolved solids & 134605 & $\mathrm{mg} / \mathrm{kg}$ sol' $\mathrm{n}$ \\
\hline Elect. conductivity & 29709.71 & $\mathrm{uS} / \mathrm{cm}$ (or umho $/ \mathrm{cm})$ \\
\hline Hardness & 0.00 & $\mathrm{mg} / \mathrm{kg}$ sol'n as $\mathrm{CaCO}$ \\
\hline carbonate & 0.00 & $\mathrm{mg} / \mathrm{kg}$ sol'n as $\mathrm{CaCO} 3$ \\
\hline non-carbonate & 0.00 & $\mathrm{mg} / \mathrm{kg}$ sol' $\mathrm{n}$ as $\mathrm{CaCO} 3$ \\
\hline Carbonate alkalinity & 11319.97 & $\mathrm{mg} / \mathrm{kg}$ sol'n as $\mathrm{CaCO} 3$ \\
\hline Water type & $\mathrm{NH} 4-\mathrm{HCO} 3$ & \\
\hline Bulk volume & $1.06 \mathrm{e}+03$ & $\mathrm{~cm} 3$ \\
\hline Fluid volume & $1.06 e+03$ & $\mathrm{~cm} 3$ \\
\hline Mineral volume & 0.00 & $\mathrm{~cm} 3$ \\
\hline Inert volume & 0.00 & $\mathrm{~cm} 3$ \\
\hline Porosity & 100. & $\%$ \\
\hline Permeability & 98.7 & $\mathrm{~cm} 2$ \\
\hline
\end{tabular}

$\begin{array}{lllr}\text { Nernst redox couples } & \text { Eh (volts) } & \text { pe } \\ 8 \mathrm{e}-+10 \mathrm{H}++2 \mathrm{HCO}-=4 \mathrm{H} 2 \mathrm{O}+\text { Acetic_acid(aq) } & -0.1493 & -2.5244 \\ 2 \mathrm{e}- & +2 \mathrm{H}++\mathrm{HCO}-+\mathrm{NH} 3(\mathrm{aq})=3 \mathrm{H} 2 \mathrm{O}+\mathrm{CN}- & -0.7032 & -11.8869 \\ 2 \mathrm{e}- & +3 \mathrm{H}++\mathrm{HCO3}-\mathrm{H} 2 \mathrm{O}+\text { Formic_acid(aq) } & -0.2571 & -4.3456 \\ 2 \mathrm{e}- & +2 \mathrm{H}++ \text { Formic_acid(aq) }=\mathrm{H} 2 \mathrm{O}+.5 \text { Acetic_a }-0.0416 & -0.7033\end{array}$

No minerals in system.

$\begin{array}{lrrrr}\text { Aqueous species } & \text { molality } & \mathrm{mg} / \mathrm{kg} \text { sol } \mathrm{n} & \text { act. coef. } & \text { log act. } \\ \text { CO2(aq) } & 2.350 & 8.949 \mathrm{e}+04 & 1.0000 & 0.3710 \\ \mathrm{H} 2 \mathrm{~S}(\mathrm{aq}) & 0.5957 & 1.757 \mathrm{e}+04 & 1.0000 & -0.2250 \\ \mathrm{NH} 4+ & 0.3716 & 5801 . & 0.6416 & -0.6227 \\ \text { HCO3- } & 0.2613 & 1.380 \mathrm{e}+04 & 0.6950 & -0.7408 \\ \text { HCN }(\mathrm{aq}) & 0.07777 & 1819 . & 1.0000 & -1.1092 \\ \text { HSO3- } & 0.06829 & 4791 . & 0.6950 & -1.3236 \\ \text { HS- } & 0.01543 & 441.7 & 0.6789 & -1.9797 \\ \text { Cl- } & 0.007778 & 238.6 & 0.6611 & -2.2889 \\ \text { Formate } & 0.007063 & 275.2 & 0.6789 & -2.3192 \\ \text { F- } & 0.006075 & 99.89 & 0.6789 & -2.3846 \\ \text { S03-- } & 0.002215 & 153.4 & 0.2284 & -3.2961\end{array}$


A. Bouquet et al.: Endogenous radiolysis in chondritic bodies

$\begin{array}{lrrrr}\text { Acetate } & 0.001056 & 53.95 & 0.7098 & -3.1252 \\ \text { NH4CH3COO(aq) } & 0.0002915 & 19.45 & 1.0000 & -3.5353 \\ \text { Acetamide(aq) } & 0.0002905 & 14.85 & 1.0000 & -3.5369 \\ \text { Acetic_acid(aq) } & 0.0002506 & 13.02 & 1.0000 & -3.6010 \\ \text { Br- } & 0.0001667 & 11.52 & 0.6611 & -3.9579 \\ \text { Formic_acid(aq) } & 0.0001588 & 6.325 & 1.0000 & -3.7991 \\ \text { HF(aq) } & 3.552 \mathrm{e}-05 & 0.6150 & 1.0000 & -4.4495 \\ \text { H2SO3(aq) } & 2.826 \mathrm{e}-05 & 2.008 & 1.0000 & -4.5488 \\ \mathrm{NH3}(\mathrm{aq}) & 2.340 \mathrm{e}-05 & 0.3449 & 1.0000 & -4.6307 \\ \mathrm{SO2}(\mathrm{aq}) & 2.013 \mathrm{e}-05 & 1.116 & 1.0000 & -4.6962 \\ \mathrm{CN}- & 1.168 \mathrm{e}-05 & 0.2631 & 0.6611 & -5.1122 \\ \mathrm{H}+ & 7.295 \mathrm{e}-06 & 0.006363 & 0.8017 & -5.2329 \\ \mathrm{CO3-}- & 6.377 \mathrm{e}-06 & 0.3312 & 0.2284 & -5.8367 \\ \mathrm{NH} 4(\mathrm{CH} 3 \mathrm{COO}) 2- & 2.320 \mathrm{e}-07 & 0.02733 & 0.6950 & -6.7926 \\ \mathrm{HF} 2- & 5.089 \mathrm{e}-08 & 0.001718 & 0.6950 & -7.4513 \\ \mathrm{HCl}(\mathrm{aq}) & 6.430 \mathrm{e}-09 & 0.0002029 & 1.0000 & -8.1918 \\ \mathrm{H} 2 \mathrm{~F} 2(\mathrm{aq}) & 3.411 \mathrm{e}-09 & 0.0001181 & 1.0000 & -8.4672 \\ \text { OH- } & 2.546 \mathrm{e}-09 & 3.748 \mathrm{e}-05 & 0.6789 & -8.7623 \\ \text { Urea(aq) } & 2.493 \mathrm{e}-09 & 0.0001296 & 1.0000 & -8.6032 \\ \mathrm{~S}-- & 8.444 \mathrm{e}-10 & 2.343 \mathrm{e}-05 & 0.2464 & -9.6819\end{array}$

Mineral saturation states $\log \mathrm{Q} / \mathrm{K}$

$\log \mathrm{Q} / \mathrm{K}$

Ice -0.1388

partial

$\begin{array}{lrcrr}\text { Gases } & \text { press. (bar) } & \text { fugacity } & \text { fug. coef. } & \text { log fug. } \\ \mathrm{CO} 2(\mathrm{~g}) & 69.52 & 69.17 & 0.9949 & 1.8399 \\ \mathrm{H} 2 \mathrm{~S}(\mathrm{~g}) & 5.842 & 5.797 & 0.9923 & 0.7632 \\ \mathrm{H} 2 \mathrm{~g}(\mathrm{~g}) & 0.02732 & 0.02597 & 0.9508 & -1.5855 \\ \mathrm{NH}(\mathrm{g}) & 3.771 \mathrm{e}-07 & 3.738 \mathrm{e}-07 & 0.9913 & -6.4273 \\ \mathrm{HF}(\mathrm{g}) & 1.861 \mathrm{e}-09 & 1.861 \mathrm{e}-09 & 1.000^{*} & -8.7302 \\ \mathrm{HCl}(\mathrm{g}) & 1.488 \mathrm{e}-14 & 1.488 \mathrm{e}-14 & 1.000^{*} & -13.8273 \\ \mathrm{HBr}(\mathrm{g}) & 8.466 \mathrm{e}-19 & 8.466 \mathrm{e}-19 & 1.000^{*} & -18.0723\end{array}$

*no data, gas taken to be ideal

\begin{tabular}{lrrrr} 
& & \multicolumn{2}{c}{ In fluid } & \multicolumn{2}{c}{ Sorbed } \\
Original basis total moles & moles & \multicolumn{1}{c}{$\mathrm{mg} / \mathrm{kg}$} & $\mathrm{moles}$ \\
$\mathrm{Hg} / \mathrm{kg}$
\end{tabular}

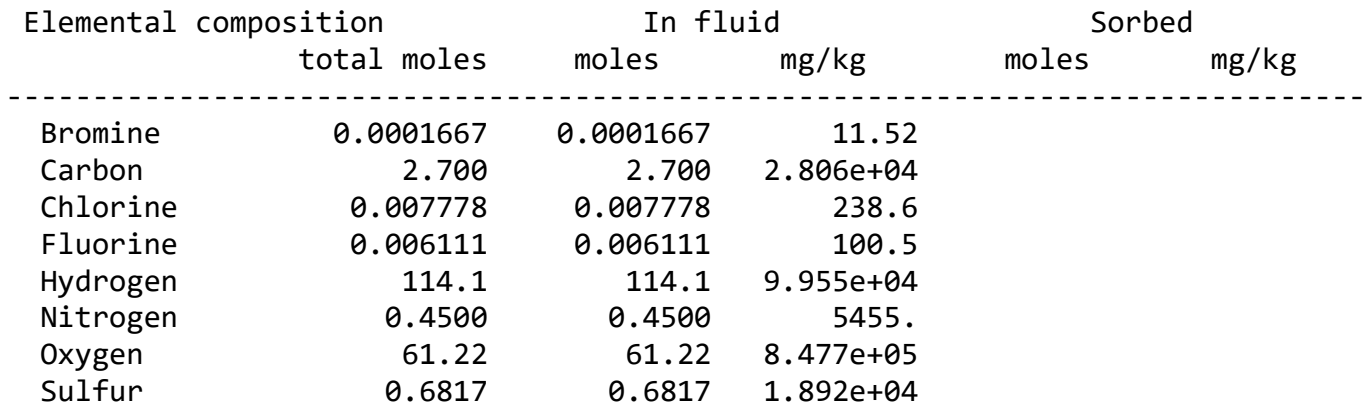


Mixture limited to water and $\mathrm{CO} 2$.

\begin{tabular}{|c|c|c|}
\hline $\begin{array}{l}\text { Temperature }=25.0 \\
\mathrm{pH}=2.964\end{array}$ & Pressure & $=1.013 \mathrm{bar}$ \\
\hline Ionic strength & 0.001127 & molal \\
\hline Activity of water & 1.000000 & \\
\hline Solvent mass & 1.0000 & $\mathrm{~kg}$ \\
\hline Solution mass & 1.1149 & $\mathrm{~kg}$ \\
\hline Mineral mass & 0.0000 & $\mathrm{~kg}$ \\
\hline Fluid density & 1.069 & $\mathrm{~g} / \mathrm{cm} 3$ \\
\hline compressibility & $3.998 e-05$ & /bar \\
\hline expansivity & 0.0002369 & /C \\
\hline viscosity & 0.009 & poise \\
\hline Chlorinity & 0.000000 & molal \\
\hline Dissolved solids & 103087 & $\mathrm{mg} / \mathrm{kg}$ sol'n \\
\hline Elect. conductivity $=$ & 439.25 & $\mathrm{uS} / \mathrm{cm}$ (or umho/cm) \\
\hline Hardness & 0.00 & $\mathrm{mg} / \mathrm{kg}$ sol'n as $\mathrm{CaCO}$ \\
\hline carbonate & 0.00 & $\mathrm{mg} / \mathrm{kg}$ sol' $\mathrm{n}$ as $\mathrm{CaCO}$ \\
\hline non-carbonate & 0.00 & $\mathrm{mg} / \mathrm{kg}$ sol'n as $\mathrm{CaCO} 3$ \\
\hline Carbonate alkalinity= & 50.59 & $\mathrm{mg} / \mathrm{kg}$ sol'n as $\mathrm{CaCO} 3$ \\
\hline Water type & $\mathrm{H}-\mathrm{HCO} 3$ & \\
\hline Bulk volume & $1.04 \mathrm{e}+03$ & $\mathrm{~cm} 3$ \\
\hline Fluid volume & $1.04 \mathrm{e}+03$ & $\mathrm{~cm} 3$ \\
\hline Mineral volume & 0.00 & $\mathrm{~cm} 3$ \\
\hline Inert volume & 0.00 & $\mathrm{~cm} 3$ \\
\hline Porosity & 100. & $\%$ \\
\hline Permeability & 98.7 & $\mathrm{~cm} 2$ \\
\hline
\end{tabular}

No minerals in system.

$\begin{array}{lrrrr}\text { Aqueous species } & \text { molality } & \mathrm{mg} / \mathrm{kg} \text { sol' } \mathrm{n} & \text { act. coef. } & \text { log act. } \\ \mathrm{CO}(\mathrm{aq}) & 2.610 & 1.030 \mathrm{e}+05 & 1.0000 & 0.4166 \\ \mathrm{H}+ & 0.001127 & 1.019 & 0.9648 & -2.9636 \\ \mathrm{HCO}- & 0.001127 & 61.68 & 0.9629 & -2.9644 \\ \mathrm{CO}-\mathrm{-} & 5.442 \mathrm{e}-11 & 2.929 \mathrm{e}-06 & 0.8602 & -10.3296 \\ \mathrm{OH}- & 9.661 \mathrm{e}-12 & 1.474 \mathrm{e}-07 & 0.9628 & -11.0315\end{array}$

Mineral saturation states

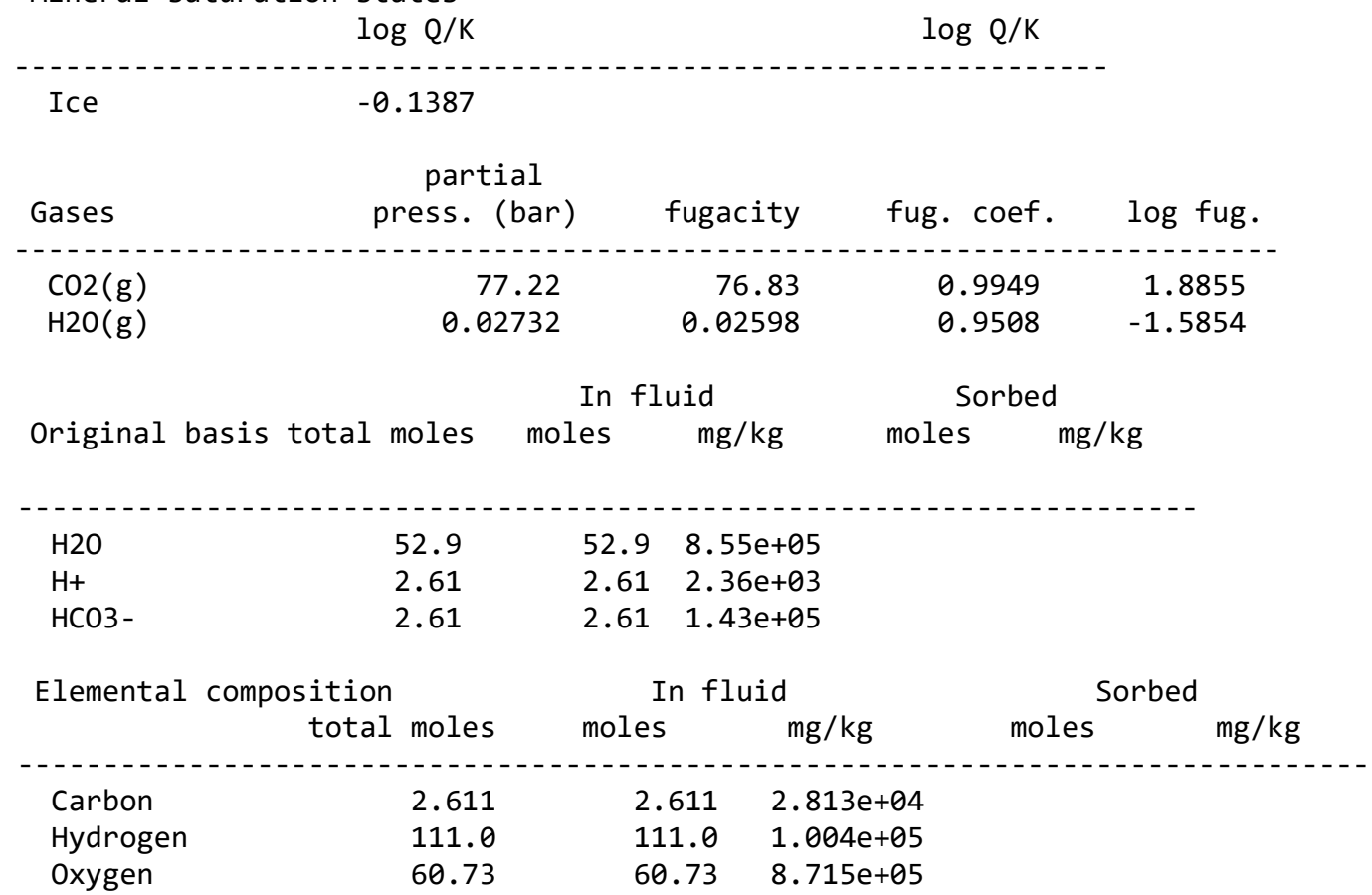


A. Bouquet et al.: Endogenous radiolysis in chondritic bodies

Ammonia removed from the volatile mixture.

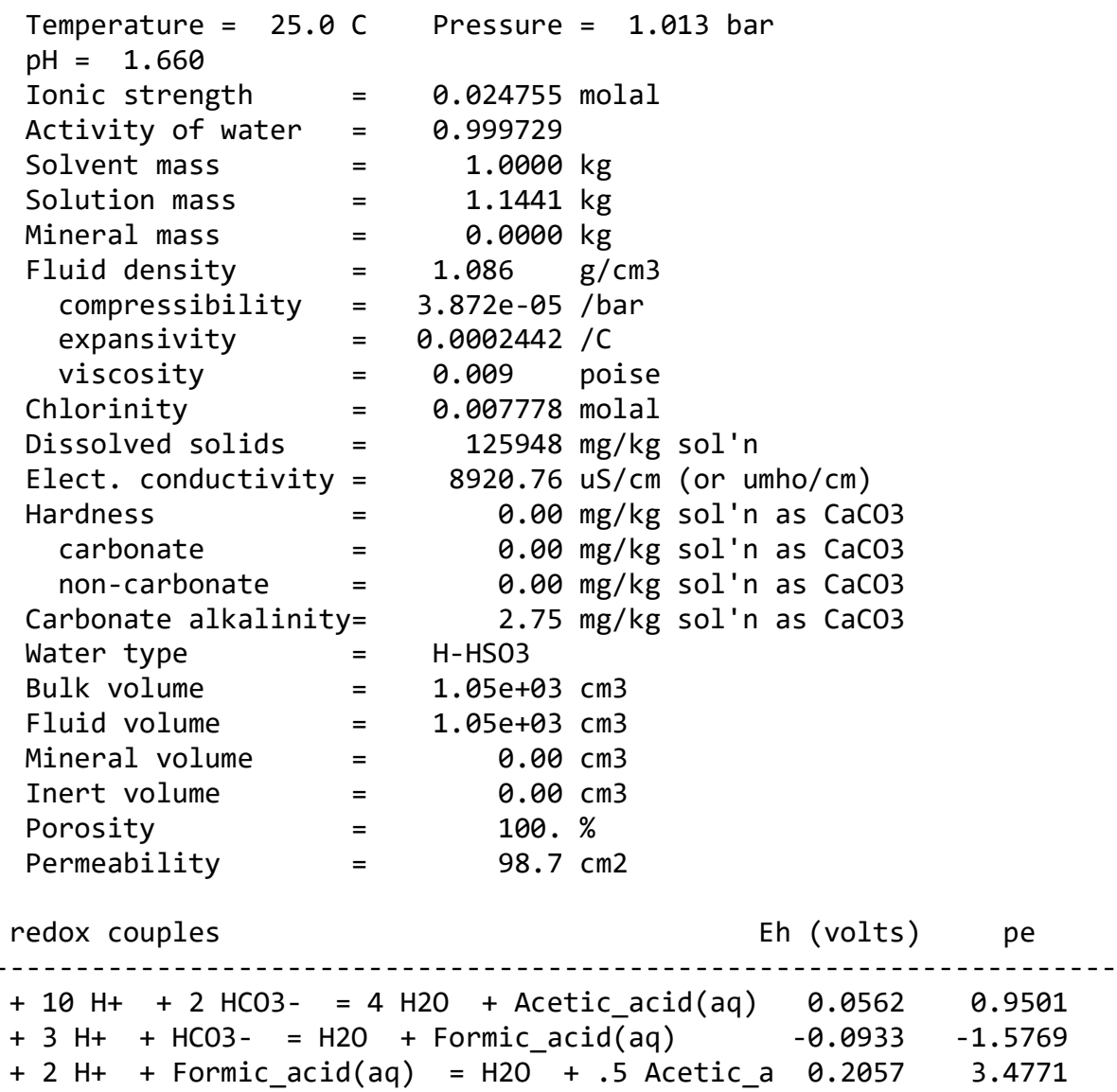

No minerals in system.

$\begin{array}{lrrrr}\text { Aqueous species } & \text { molality } & \mathrm{mg} / \mathrm{kg} \text { sol'n } & \text { act. coef. } & \text { log act. } \\ \text { CO2(aq) } & 2.611 & 1.004 \mathrm{e}+05 & 1.0000 & 0.4168 \\ \text { H2S(aq) } & 0.6111 & 1.820 \mathrm{e}+04 & 1.0000 & -0.2139 \\ \text { HCN(aq) } & 0.07778 & 1837 . & 1.0000 & -1.1091 \\ \text { H2SO3(aq) } & 0.03157 & 2265 . & 1.0000 & -1.5007 \\ \text { H+ } & 0.02475 & 21.81 & 0.8833 & -1.6602 \\ \text { SO2(aq) } & 0.02248 & 1259 . & 1.0000 & -1.6481 \\ \text { HSO3- } & 0.01650 & 1169 . & 0.8597 & -1.8482 \\ \text { Cl- } & 0.007747 & 240.1 & 0.8538 & -2.1795 \\ \text { Formic_acid(aq) } & 0.007155 & 287.8 & 1.0000 & -2.1454 \\ \text { HF(aq) } & 0.005726 & 100.1 & 1.0000 & -2.2422 \\ \text { Acetic_acid(aq) } & 0.001887 & 99.05 & 1.0000 & -2.7242 \\ \text { F- } & 0.0002075 & 3.446 & 0.8568 & -3.7500\end{array}$


A\&A 653, A59 (2021)

$\begin{array}{lrrrr}\text { Br- } & 0.0001667 & 11.64 & 0.8538 & -3.8468 \\ \text { H2F2(aq) } & 8.861 \mathrm{e}-05 & 3.099 & 1.0000 & -4.0525 \\ \text { Formate } & 6.744 \mathrm{e}-05 & 2.654 & 0.8568 & -4.2382 \\ \text { HCO3- } & 6.279 \mathrm{e}-05 & 3.349 & 0.8597 & -4.2678 \\ \text { HCl(aq) } & 3.092 \mathrm{e}-05 & 0.9854 & 1.0000 & -4.5097 \\ \text { HS- } & 3.356 \mathrm{e}-06 & 0.09700 & 0.8568 & -5.5414 \\ \text { Acetate } & 1.750 \mathrm{e}-06 & 0.09032 & 0.8625 & -5.8212 \\ \text { HF2- } & 2.859 \mathrm{e}-07 & 0.009748 & 0.8597 & -6.6094 \\ \text { SO3-- } & 7.356 \mathrm{e}-08 & 0.005148 & 0.5495 & -7.3934 \\ \text { CN- } & 2.420 \mathrm{e}-09 & 5.503 \mathrm{e}-05 & 0.8538 & -8.6848 \\ \text { OH- } & 5.397 \mathrm{e}-13 & 8.022 \mathrm{e}-09 & 0.8568 & -12.3350 \\ \text { CO3-- } & 2.107 \mathrm{e}-13 & 1.105 \mathrm{e}-08 & 0.5495 & -12.9363 \\ \mathrm{~S}-- & 2.745 \mathrm{e}-17 & 7.692 \mathrm{e}-13 & 0.5563 & -16.8162\end{array}$

Mineral saturation states

\begin{tabular}{|c|c|c|c|c|}
\hline 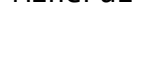 & $\log Q / K$ & & $\log Q / K$ & \\
\hline Ice & -0.1388 & & & \\
\hline Gases & $\begin{array}{c}\text { partial } \\
\text { press. (bar) }\end{array}$ & fugacity & fug. coef. & log fug. \\
\hline 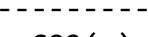 & -------1 & --1 & $----1--1$ & 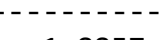 \\
\hline $\mathrm{CO} 2(\mathrm{~g})$ & 77.25 & 76.86 & 0.9949 & 1.8857 \\
\hline $\mathrm{H} 2 \mathrm{~S}(\mathrm{~g})$ & 5.993 & 5.947 & 0.9923 & 0.7743 \\
\hline $\mathrm{H} 2 \mathrm{O}(\mathrm{g})$ & 0.02732 & 0.02597 & 0.9508 & -1.5855 \\
\hline $\mathrm{HF}(\mathrm{g})$ & $3.000 e-07$ & $3.000 e-07$ & $1.000 *$ & -6.5229 \\
\hline $\mathrm{HCl}(\mathrm{g})$ & $7.157 e-11$ & $7.157 e-11$ & $1.000 *$ & -10.1452 \\
\hline $\operatorname{HBr}(\mathrm{g})$ & $4.088 e-15$ & $4.088 e-15$ & $1.000 *$ & -14.3885 \\
\hline
\end{tabular}

*no data, gas taken to be ideal

\begin{tabular}{lrrrr} 
& & \multicolumn{2}{c}{ In fluid } & \multicolumn{2}{c}{ Sorbed } \\
Original basis total moles & moles & $\mathrm{mg} / \mathrm{kg}$ & $\mathrm{moles}$ & $\mathrm{mg} / \mathrm{kg}$ \\
H2O & 52.9 & 52.9 & $8.33 \mathrm{e}+05$ & \\
Acetic_acid(aq & 0.00189 & 0.00189 & 99.1 & \\
Br- & 0.000167 & 0.000167 & 11.6 & \\
CN- & 0.0778 & 0.0778 & $1.77 \mathrm{e}+03$ \\
Cl- & 0.00778 & 0.00778 & 241. \\
F- & 0.00611 & 0.00611 & 101. \\
Formic_acid(aq & 0.00722 & 0.00722 & 291. \\
H+ & 3.46 & 3.46 & $3.04 \mathrm{e}+03$ \\
HCO3- & 2.61 & 2.61 & $1.39 \mathrm{e}+05$ \\
HS- & 0.611 & 0.611 & $1.77 \mathrm{e}+04$ \\
S03-- & 0.0706 & 0.0706 & $4.94 \mathrm{e}+03$
\end{tabular}

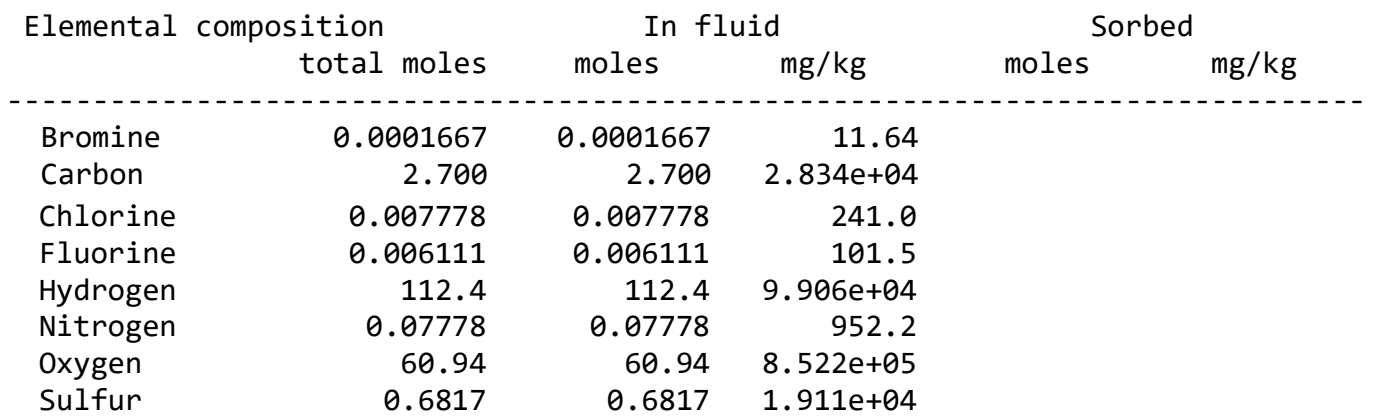


A. Bouquet et al.: Endogenous radiolysis in chondritic bodies

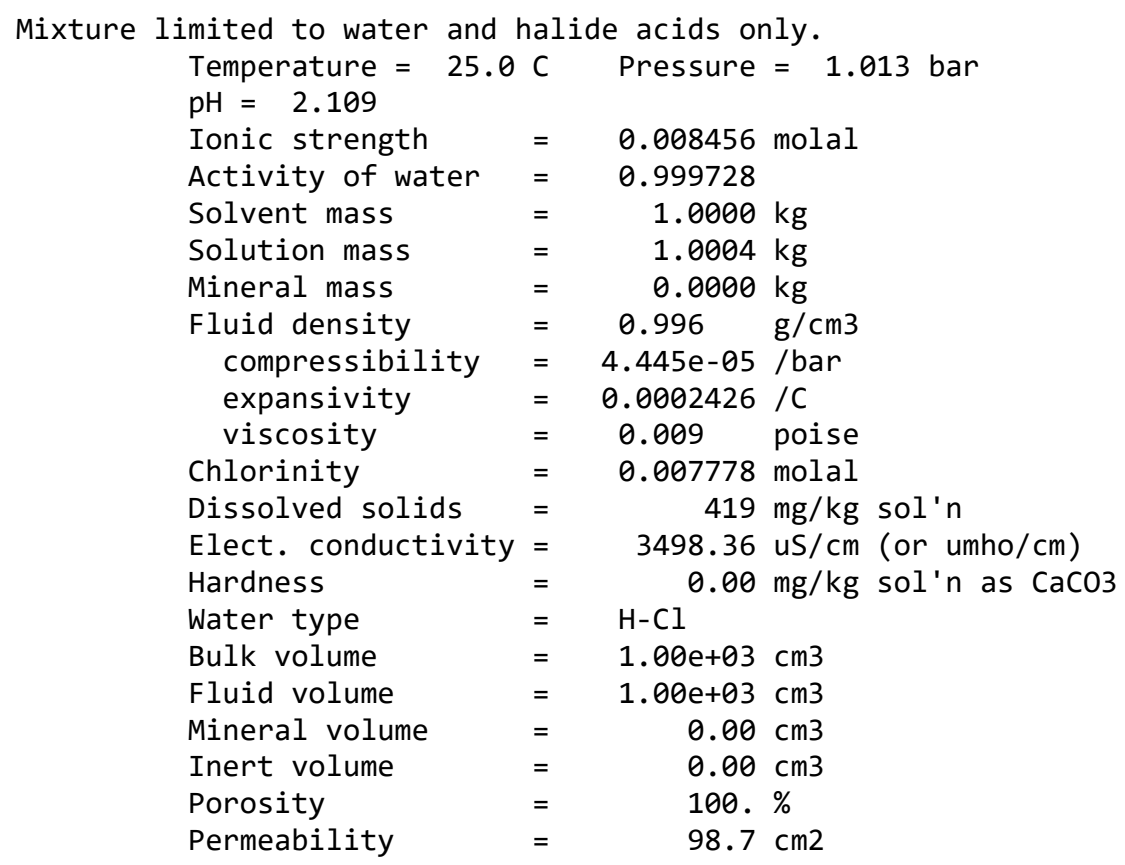

No minerals in system.

\begin{tabular}{lrrrr} 
Aqueous species & molality & $\mathrm{mg} / \mathrm{kg}$ sol' $\mathrm{n}$ & act. coef. & log act. \\
\hline $\mathrm{H}+$ & 0.008456 & 8.519 & 0.9191 & -2.1095 \\
$\mathrm{Cl}-$ & 0.007766 & 275.2 & 0.9062 & -2.1526 \\
$\mathrm{HF}(\mathrm{aq})$ & 0.005428 & 108.5 & 1.0000 & -2.2654 \\
$\mathrm{~F}-$ & 0.0005226 & 9.924 & 0.9074 & -3.3240 \\
$\mathrm{Br}-$ & 0.0001667 & 13.31 & 0.9062 & -3.8209 \\
$\mathrm{H} 2 \mathrm{~F} 2(\mathrm{aq})$ & $7.963 \mathrm{e}-05$ & 3.185 & 1.0000 & -4.0989 \\
$\mathrm{HCl}(\mathrm{aq})$ & $1.169 \mathrm{e}-05$ & 0.4262 & 1.0000 & -4.9320 \\
$\mathrm{HF}-$ & $6.839 \mathrm{e}-07$ & 0.02667 & 0.9086 & -6.2066 \\
$\mathrm{OH}-$ & $1.434 \mathrm{e}-12$ & $2.437 \mathrm{e}-08$ & 0.9074 & -11.8858
\end{tabular}

Mineral saturation states

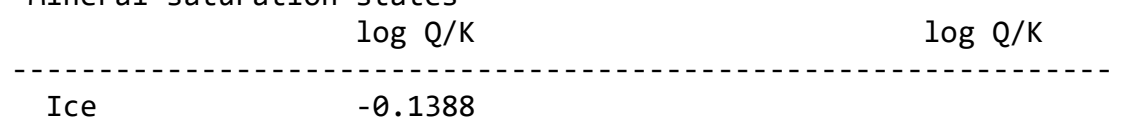

\begin{tabular}{|c|c|c|c|c|}
\hline Gases & $\begin{array}{c}\text { partial } \\
\text { press. (bar) }\end{array}$ & fugacity & fug. coef. & log fug. \\
\hline $\mathrm{H} 2 \mathrm{O}(\mathrm{g})$ & 0.02732 & 0.02597 & 0.9508 & -1.5855 \\
\hline $\mathrm{HF}(\mathrm{g})$ & $2.844 \mathrm{e}-07$ & $2.844 \mathrm{e}-07$ & $1.000 *$ & -6.5461 \\
\hline $\mathrm{HCl}(\mathrm{g})$ & $2.707 e-11$ & $2.707 e-11$ & $1.000 *$ & -10.5675 \\
\hline $\operatorname{HBr}(\mathrm{g})$ & $1.542 \mathrm{e}-15$ & $1.542 \mathrm{e}-15$ & $1.000 *$ & -14.8119 \\
\hline
\end{tabular}


*no data, gas taken to be ideal

\begin{tabular}{|c|c|c|c|c|c|}
\hline \multirow{2}{*}{\multicolumn{2}{|c|}{ Original basis total moles }} & \multicolumn{2}{|c|}{ In fluid } & \multicolumn{2}{|c|}{ Sorbed } \\
\hline & & moles & $\mathrm{mg} / \mathrm{kg}$ & moles & $\mathrm{mg} / \mathrm{kg}$ \\
\hline---1 & - - - - - & -- & $---1--1$ & & \\
\hline $\mathrm{H} 2 \mathrm{O}$ & 55.5 & 55.5 & $1.00 \mathrm{e}+06$ & & \\
\hline $\mathrm{Br}-$ & 0.000167 & 0.000167 & 13.3 & & \\
\hline $\mathrm{Cl}-$ & 0.00778 & 0.00778 & 276. & & \\
\hline F- & 0.00611 & 0.00611 & 116. & & \\
\hline $\mathrm{H}+$ & 0.0141 & 0.0141 & 14.2 & & \\
\hline
\end{tabular}

\begin{tabular}{|c|c|c|c|c|c|}
\hline \multicolumn{2}{|c|}{ Elemental composition } & \multicolumn{2}{|c|}{ In fluid } & \multicolumn{2}{|c|}{ Sorbed } \\
\hline & tal moles & moles & $\mathrm{mg} / \mathrm{kg}$ & moles & $\mathrm{mg} / \mathrm{kg}$ \\
\hline Bromine & 0.0001667 & 0.0001667 & 13.31 & & \\
\hline Chlorine & 0.007778 & 0.007778 & 275.6 & & \\
\hline Fluorine & 0.006111 & 0.006111 & 116.1 & & \\
\hline Hydrogen & 111.0 & 111.0 & $1.119 \mathrm{e}+05$ & & \\
\hline oxygen & 55.51 & 55.51 & $8.877 e+05$ & & \\
\hline
\end{tabular}

\section{Appendix B: Effect of enhanced yields in sedimentary environments}

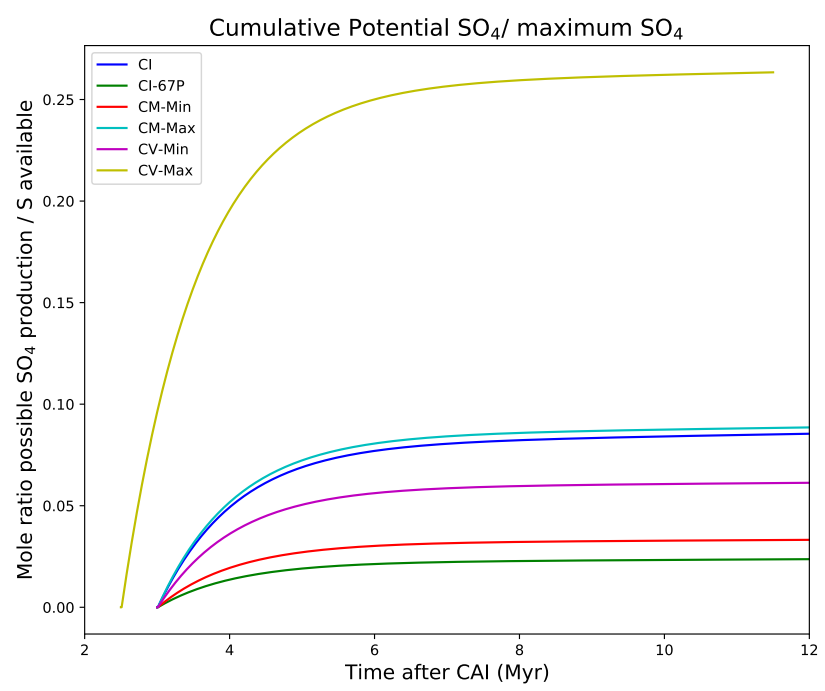

Fig. B.1. Same calculation as Fig. 1, but using yields derived from the maximum values of Sauvage et al. (2021). The $\alpha$-particle yield is enhanced by a factor of 27 , and the $\gamma$-ray and electron yields by a factor of 8.16 .

Recent experimental work (Sauvage et al. 2021) indicates that the yield of endogenous radiolysis can be greatly enhanced depending on the mineral matrix present compared with yields obtained with pure water. $\mathrm{H}_{2}$ yields can be enhanced by a factor of 27 (compared to values in pure water) in pelagic clays for $\alpha$-particles and 8.16 for $\gamma$ rays in siliceous ooze. We assumed

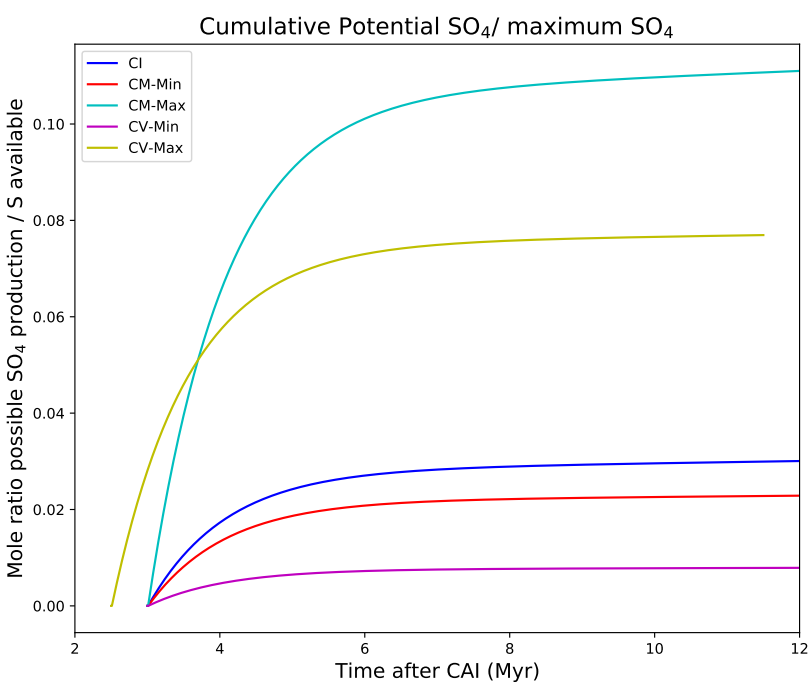

Fig. B.2. Same calculation as Fig. 2, but using yields derived from the maximum values of Sauvage et al. (2021). The $\alpha$-particle yield is enhanced by a factor of 27 , and the $\gamma$-ray and electron yields by a factor of 8.16 .

these factors also applied to oxidant yields to perform a recalculation of the results displayed in Figs. 1 and 2. As in Sauvage et al. (2021), we assumed that electron yields are enhanced by the same 8.16 factor as $\gamma$ rays; however, calculations with the original electron yields (not displayed) show that the effect is not significant. Results are detailed in Figs. B.1 and B.2. We note that we applied both yield enhancements even though they pertain to different types of sediments; however, the dominant effect is the increase of yields from $\gamma$ rays. 